US Army Corps

of Engineers ${ }_{\circledast}$

Engineer Research and

Development Center

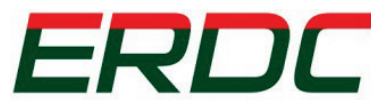

INNOVATIVE SOLUTIONS for a safer, better world

Dredging Operations and Environmental Research Program

\title{
A Guide for Using Geochemical Methods in Dredged Material, Sediment Tracking, and Sediment Budget Studies
}

Heidi M. Wadman, David W. Perkey, Jennifer M. Seiter, June 2017 Mark A. Chappell, and Brandon Lafferty

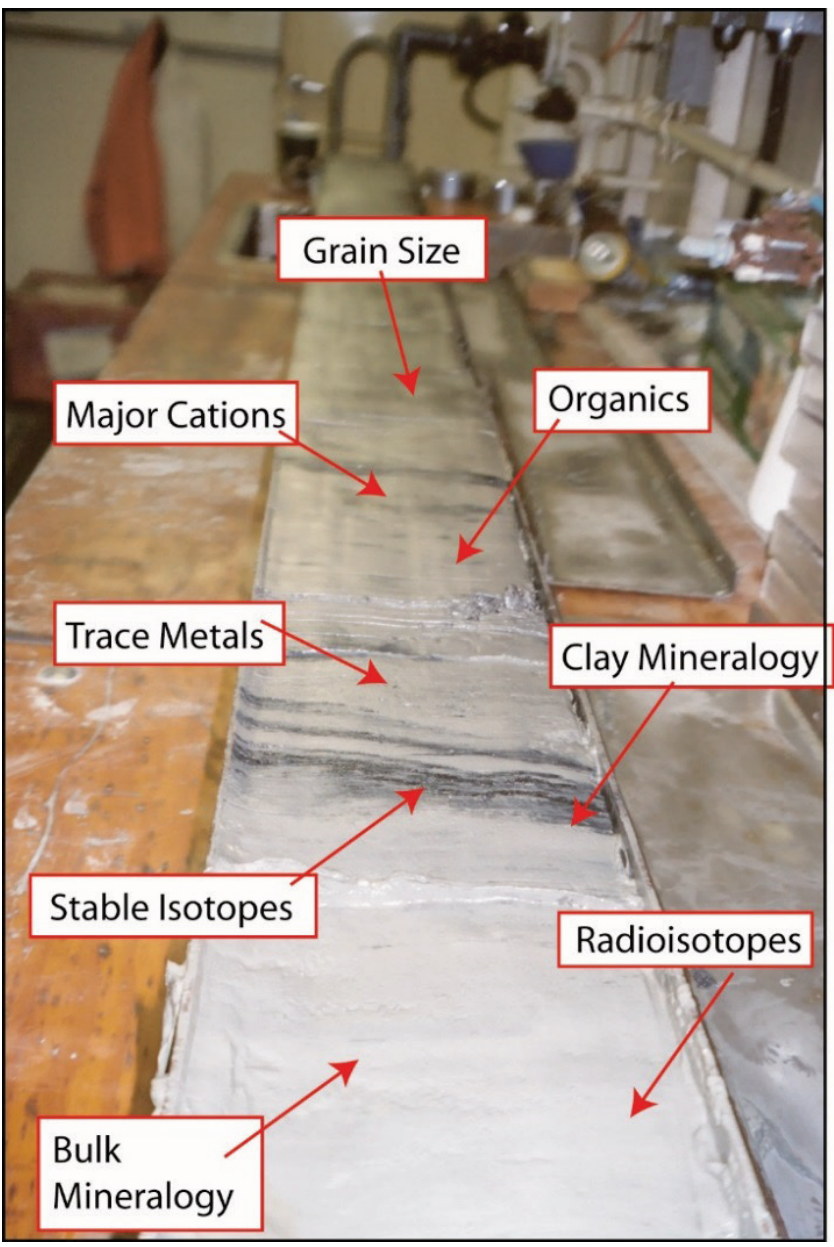


The U.S. Army Engineer Research and Development Center (ERDC) solves the nation's toughest engineering and environmental challenges. ERDC develops innovative solutions in civil and military engineering, geospatial sciences, water resources, and environmental sciences for the Army, the Department of Defense, civilian agencies, and our nation's public good. Find out more at www.erdc.usace.army.mil.

To search for other technical reports published by ERDC, visit the ERDC online library at http://acwc.sdp.sirsi.net/client/default. 


\section{A Guide for Using Geochemical Methods in Dredged Material, Sediment Tracking, and Sediment Budget Studies}

Heidi M. Wadman

Coastal and Hydraulics Laboratory, Coastal Observations and Analysis Branch U.S. Army Engineer Research and Development Center Field Research Facility 1261 Duck Rd.

Kitty Hawk, NC 27949

David W. Perkey

Coastal and Hydraulics Laboratory, Field Data and Measurements Branch U.S. Army Engineer Research and Development Center 3909 Halls Ferry Road

Vicksburg, MS 39180-6199

Jennifer M. Seiter, Mark A. Chappell, Brandon Lafferty

Environmental Laboratory

U.S. Army Engineer Research and Development Center

3909 Halls Ferry Road

Vicksburg, MS 39180-6199

Final report

Approved for public release; distribution is unlimited.

Prepared for Dredging Operations and Environmental Research Program

Coastal and Hydraulics Laboratory

U.S. Army Engineer Research and Development Center

Vicksburg, MS 39180-6199

Under Project 449021, "Geochemical and Other Tracers for Dredged Material Fate" 


\section{Abstract}

Effective regional sediment management has the potential to significantly reduce operating costs for the U.S. Army Corps of Engineers but only if the ultimate sources and sinks of coastal sediment are fully quantified.

Geochemical sedimentary markers provide a well-established methodology for fingerprinting the various sources and time frames over which sediment accumulates in regions of concern. This report outlines the basic methodology of how different geochemical signatures can be utilized to identify sources and fates of sediment. These methodologies are then showcased in example case studies (real and hypothetical) that address issues pertinent to the mission of the U.S. Army Corps of Engineers.

DISCLAIMER: The contents of this report are not to be used for advertising, publication, or promotional purposes. Citation of trade names does not constitute an official endorsement or approval of the use of such commercial products. All product names and trademarks cited are the property of their respective owners. The findings of this report are not to be construed as an official Department of the Army position unless so designated by other authorized documents. 


\section{Contents}

Abstract.................................................................................................................................. if

Figures and Tables............................................................................................................iv

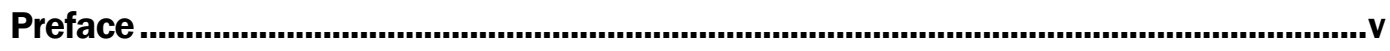

Unit Conversion Factors......................................................................................................

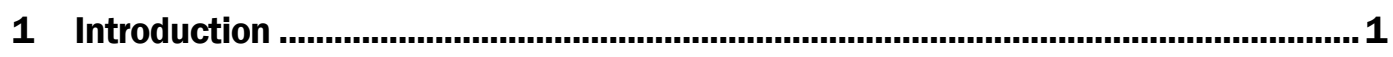

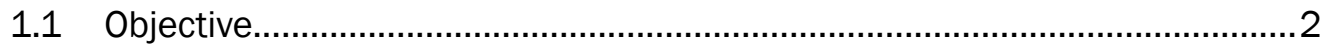

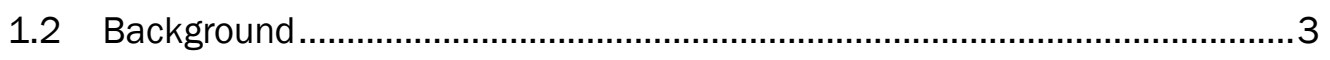

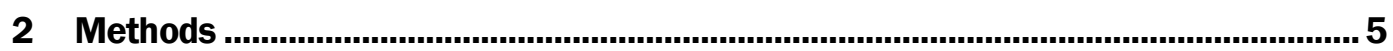

2.1 Elemental composition and mineralogy ................................................... 5

2.2 Sedimentary stable isotope tracers ............................................................ 7

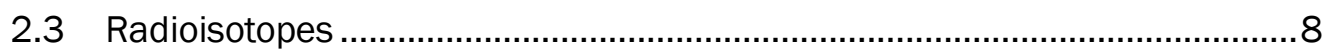

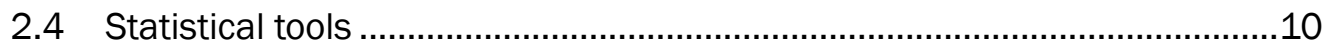

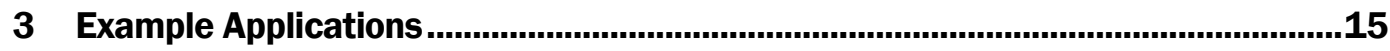

3.1 Sediment budgets via geochemical markers ...........................................15

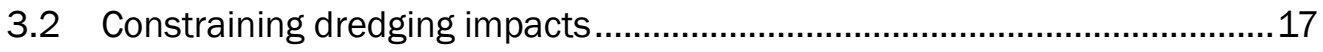

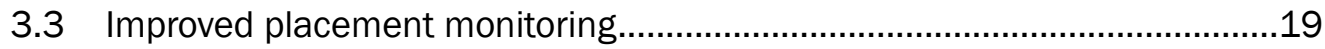

3.4 Sediment transport post dam removal ...................................................... 20

3.5 Offshore fate of terrestrial sediment..........................................................21

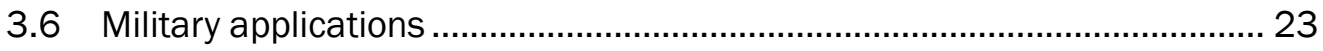

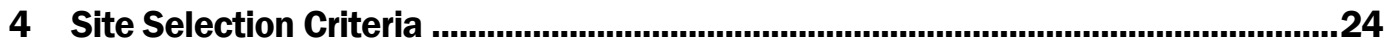

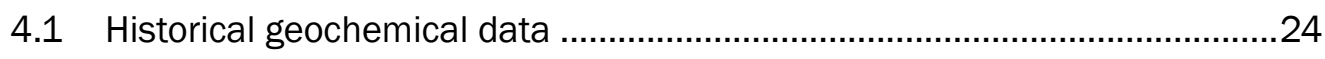

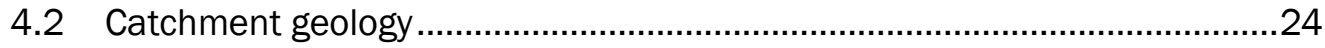

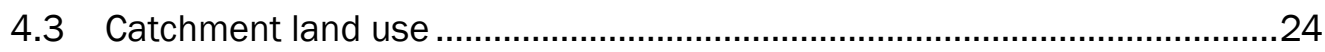

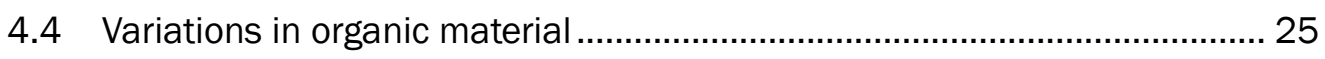

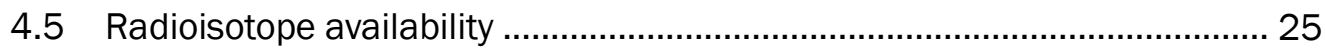

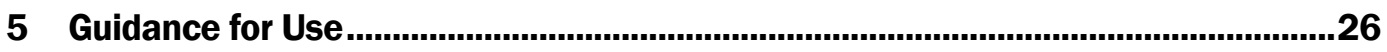

6 Summary $\ldots \ldots \ldots \ldots \ldots \ldots \ldots \ldots$

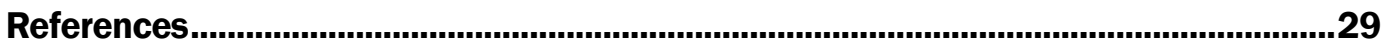

Report Documentation Page 


\section{Figures and Tables}

\section{Figures}

Figure 1. Plots showing the results of an optimized PCA model containing two PCs explaining 94\% of the variance in the data. The score plot (upper) describes the relationships among the samples while the lower plot (loading) describes the relationships among the variables.

Figure 2. Depiction of ambient suspended and bottom sediment from oceanic and riverine sources (left panel). Right panel shows the inclusion of dredgesuspended sediment. Dashed red box indicates the likely limitation of dredge plume detection without the use of geochemical markers.

\section{Tables}

Table 1. Four of the most commonly used radioisotopes in geochemical fingerprinting.

Table 2. The most commonly used radioisotope ratios in the context of geochemical fingerprinting. 


\section{Preface}

This study was conducted for the Dredging Operations and Environmental Research (DOER) Program under Project 449021, "Geochemical and Other Tracers for Dredged Material Fate.” The DOER Program Manager was Dr. Todd S. Bridges.

The work was performed by the Coastal Observations and Analysis Branch of the Flood and Storm Protection Division, U.S. Army Engineer Research and Development Center (ERDC), Coastal and Hydraulics Laboratory (CHL). The report was prepared under the direction of Dr. Jeff Waters, Chief of the Coastal Observations and Analysis Branch; Dr. Cary Talbot, Chief of the Flood and Storm Protection Division; Mr. Jeffrey R. Eckstein, Acting Deputy Director of CHL; and Mr. José E. Sánchez, Director of CHL.

Work was performed also by the Field Data and Measurements Branch, ERDC-CHL, and the Environmental Laboratory, ERDC.

COL Bryan S. Green was the Commander of ERDC, and Dr. David W. Pittman was the Director. 


\section{Unit Conversion Factors}

\begin{tabular}{|l|c|l|}
\hline Multiply & By & To Obtain \\
\hline feet & 0.3048 & meters \\
\hline inches & 0.0254 & meters \\
\hline
\end{tabular}




\section{Introduction}

Quantification of sediment erosion, transport, and accumulation in aqueous regions is a critical component of the U.S. Army Corps of Engineers (USACE) missions. USACE dredging projects result in the removal of more than 200 million $\mathrm{yd}^{3}$ of material annually. Accurate sediment budgets derived, at least in part, from sediment fingerprinting techniques assist districts to predict dredging needs over the lifespan of a given project and serve to better predict sources of infilling sediments. These data enable districts to develop improved cost-saving sediment mitigation techniques. The same techniques may also allow better tracking and quantification of dredge-suspended sediment fate as it is transported downstream. Sediment fingerprinting also provides a tool for more accurate tracking of sediment released either intentionally or unintentionally from dams during removal or breaching. With respect to military bases, the tracking of potentially contaminated sediment with geochemical fingerprinting from Formerly Used Defense Sites (FUDS), testing ranges, and similar areas of concern can be more accurate than more traditional methods.

Sediment transport is a transient process, due to natural resuspension as well as anthropogenic activities (e.g., dredging), and occurs at widely varying temporal and spatial scales. Currently, sediment transport through a region can be observed to some extent from a variety of remote sensing techniques such as optical or acoustic methods (e.g., Nichols et al. 1990; Hamilton et al. 1998; Hitchcock and Bell 2004; Wu et al. 2007). Unfortunately, these methods do not provide any information regarding the source of the sediment being transported. Effective regional sediment management has the potential to minimize sediment accumulation, thus reducing dredging costs and environmental impacts. Specific challenges to effective sediment management include (a) identifying the source and accumulation history of sediment infilling an area of interest (i.e., channels/harbors/bays/reservoirs) and (b) improving sediment tracking moving from an area of interest (i.e., dredging/placement sites, reservoirs, and military installations) to better quantify the environmental impacts of sediment manipulation on local ecosystems. 
Sedimentary geochemical markers such as radioisotopes and stable isotopes, organic matter, and mineralogy/elemental composition are recognized and established methods for distinguishing between sediment sources. Currently, these geochemical methods are not routinely utilized by the USACE to monitor the transport and fate of sediments moving into or out of a dredging-impacted environment or to quantify the sediment budget for a specific region. When used effectively, geochemical markers can be used to fingerprint the various sources of sediment being transported to and/or deposited within regional sinks (e.g., Walling 2005; Davis and Fox 2009). Further, these geochemical fingerprinting methods represent the standard methods used by the greater scientific community to delineate a local to regional sediment budget.

\subsection{Objective}

Specifically, geochemical fingerprinting of sediment will allow USACE to accomplish the following:

1. Improve USACE's ability to quantify a sediment budget for a region. Geochemical fingerprinting-based sediment budgets allow delineation of the sources of accumulating sediments and the processes by which they are deposited (e.g., consistent sedimentation vs. flood events) over a specific period of time (e.g., weeks to decades). These data can be used to determine if elevation differences previously mapped in a region reflect erosion/accretion in the region, and the time frame and source of the infilling sediments. They can also be used to quantify a sediment budget in regions where traditional bathymetric surveys are not an option (i.e., very shallow regions).

2. Identify the sources and infilling rates of accumulating sediment, including infilling contaminated sediment, within a navigable region. This information could be used to improve or develop local sediment management practices (such as diverting sediment-laden flows through flow control structures) that minimize sedimentation and thus reduce related dredging costs.

3. Better quantify the impact of dredging on ecosystem health. Dredgesuspended plumes and associated deposition are currently tracked through a variety of acoustic and optical methods. Unfortunately, these methods cannot distinguish dredge-related sediment from naturally suspended and accreting sediment. As a result, any deleterious effects of sedimentation downstream of a dredge are frequently assumed to be related to the dredging activity. Geochemical markers can potentially 
distinguish dredge-sourced sediment from natural sediment, allowing a more refined understanding of accumulation downstream of a dredge, potentially reducing USACE's mitigation responsibilities.

4. Track the resuspension, transport, and fate of sediment from a dredge material placement site for a longer period of time and at higher resolution than optical or acoustic methods alone.

5. Track the downstream transport and deposition of sediment after dam removal.

6. Quantify the source, transport pathways, and deposition of terrestrial sediment on offshore resources (e.g., coral reefs, oyster beds, submerged aquatic vegetation beds). The timeframe over which sediment is transported to these environments can sometimes also be quantified, potentially allowing for better management of the source material to reduce sedimentation on the offshore resource.

7. Identify the natural sources of sand on beaches. In addition, if sand used to nourish a beach is geochemically distinct from the native sediment, geochemical markers can be used to track the transport of the renourished sand from the beach through the larger system.

8. Identify and track transport of sediments impacted by contamination from active and abandoned military test ranges.

This technical report provides an introduction to the most commonly used markers used in geochemical fingerprinting studies, including brief explanations of their benefits and limitations. It outlines the basic criteria used to determine which markers will work best at a particular site and describes the basic steps used in analysis and interpretation of these data. Finally, both real and theoretical case studies are provided that address issues pertinent to the mission of the USACE.

\subsection{Background}

The use of geochemical fingerprinting to identify sources and sinks of suspended and accumulating sediment, and to quantify the rate and processes by which sediments accumulate, has been accepted as standard practice by the greater scientific community for decades. While volume change of sediment derived from bathymetric or digital elevation model (DEM)-based elevation change can provide a basic snapshot of sediment erosion and accumulation between two discrete time intervals, the addition of geochemical fingerprinting allows quantification of (1) the source(s) of suspended or accumulating sediment and/or (2) the rate(s) in which sediments are transported through, or accumulate within, a region. 
The accumulation rate of sediment, and by extension the hydrodynamic processes that resulted in the transport and deposition of that sediment (e.g., storm activity, daily deposition), is largely quantified by sedimentary radioisotope profiles, augmented when possible with bathymetric and volumetric change maps (e.g., Baskaran et al. 1997; Goodbred and Kueh 1998; Patchineelam et al. 1999; Gouleau et al. 2000; Noakes and Jutt 2006; Nittrouer et al. 2009; Hancock and Caitcheo 2010). The sources of those sediments are determined using a wide range of geochemical fingerprints associated with sediment particles, including radioisotopes and organic material (e.g., Redfield et al. 1963; McKee et al. 1983; Toole et al. 1987; Maksymowska et al. 2000; Waples et al. 2006; Noakes and Jutte 2006; Forrest et al. 2007; Rumolo et al. 2011; Gireeshkumar et al. 2013), elemental composition, and the mineralogy of the sediment particles themselves (e.g., Santschi et al. 1984; Buol et al. 1997; Goodbred and Kuehl 1998). The source of suspended sediment, and sometimes the time in suspension, can be quantified in a similar manner using one or more of the geochemical tools described above (e.g., Feng et al. 1998; Feng et al. 1999b).

Not every geochemical fingerprinting technique is applicable at every site, requiring a quantitative accounting of the sources and infilling rates of sediment in a region of concern. For instance, inland regions without an oceanic or large lacustrine end member will not benefit from certain isotopic (i.e., $7 \mathrm{Be} / 234 \mathrm{Th}$ ) or organic (i.e., $\mathrm{C} / \mathrm{N}$ ) ratios. Those regions might, however, benefit from the use of ${ }^{210} \mathrm{~Pb} / 7 \mathrm{Be} /{ }^{137} \mathrm{Cs}$ profiles and ratios to determine the rates of sediment accumulation. In another example, the use of stable isotopes (i.e., $\delta^{13} \mathrm{C}$ or $\delta^{15} \mathrm{~N}$ ) and/or variations in sedimentary mineralogy may be used to discern the relative percentage of sediment sourced from different regions in the watershed. Once the appropriate geochemical fingerprints have been identified and measured, quantitative interpretation of the data ranges from the simple calculation of radioisotope-based accumulation rates to a more comprehensive principal component analysis (PCA). 


\section{Methods}

In applying geochemical fingerprinting data to sediment management research, the first step is to identify the potential sources of native sediment to a region by determining their corresponding geochemical characteristics. These geochemical characteristics make up the inherent geochemical fingerprint of a region-specific sediment. Identifying the potential sources of sediment that infill a region, however, can be challenging. While some end members are obvious (i.e., freshwater and saltwater sources in an estuary), others can be more complex (e.g., discerning clay sourced from an industrial region from clay sourced from an agricultural region). However, many infilling regions have been studied by USACE for years, and a wealth of sediment data (e.g., grain size, trace metal concentration) from these regions exists. In these cases, the geochemical fingerprint is best developed by exploring the covariate relationships within the existing historical data using multivariate statistical techniques, as described later in this document. Once the native sediments and any potential source sediments for a region have been identified and characterized, additional samples can be collected from natural sinks and placement areas, further analyzed, and fingerprinted to determine the source(s) of the sediment in question using a multitiered geochemical approach. Longer sediment cores can be collected to quantify the time frame over which the sediments accumulated, from which the processes controlling sediment transport into a sink can be derived.

Finally, multivariate statistical approaches may be applied to all (historical and new) data sets to further identify trends within the sample dataset through inherent covariate relationships. These geochemical fingerprinting techniques allow for the identification of the various sources of sediment either in suspension or accumulating in a region at a much higher resolution than previously available and are described in more detail in the following sections.

\subsection{Elemental composition and mineralogy}

The elemental composition and speciation of organic material (OM) associated with sediments can yield important insight into the origin of sedimentary material. A sediment's total organic carbon (TOC) to total nitrogen (TN) ratio ( $\mathrm{C} / \mathrm{N}$ ratio) can help discern the origin of sediment grains, with terrestrial-derived $\mathrm{OM}$ possessing a higher $\mathrm{C} / \mathrm{N}$ ratio than marine-derived OM (e.g., Bordovskiy 1965; Prahl et al. 1980; Meyers 1997; 
Maksymowska et al. 2000). Specifically, marine plankton (typically making up marine-derived $\mathrm{OM}$ ) generally exhibit $\mathrm{C} / \mathrm{N}$ ratios of 6-7 while terrestrial $\mathrm{C} / \mathrm{N}$ ratios from vascular plants range from $15-40$ or greater (Redfield et al. 1963; Meyers 1994, 1997; Jaffe et al. 2001; Maksymowska et al. 2000; Forrest et al. 2007). In addition, OM C/N ratios are also indicative of different land uses. For example, forest soils typically have higher $\mathrm{C} / \mathrm{N}$ ratios than agricultural and grassland soils (Papanicolaou et al. 2003.)

While OM characteristics may be useful in identifying sediment sources, there are important limitations to this approach. For example, organic signatures do not represent conservative properties. Diagenetic processes, such as decomposition, nitrification, and denitrification, can alter the sediment $\mathrm{OM}$, and thus $\mathrm{C} / \mathrm{N}$ ratios over time. Another complicating factor in the use of $\mathrm{C} / \mathrm{N}$ ratios to determine particle history lies in the influence of grain size on ratios of OM. Specifically, there are two basic forms of OM. Particulate OM, such woody and vegetative debris, soot, and charcoal, exists as discrete particles that influence a bulk samples carbon content. Conversely, a second form of OM occurs as a film-like substance that is strongly correlated with surface area of sediment particles. Smaller particles tend to have higher surface area relative to particle volume and therefore more film-like OM content than larger particles (Hedges and Keil 1995; Meyers 1997). Measurable OM, particularly as used to derive sedimentary $\mathrm{C} / \mathrm{N}$ ratios, associated with sand-sized grains is thus distinctly different from that associated with finer material, representing material of distinct origins or diagenetic history (e.g., Prahl et al. 1994; Hedges and Keil 1995; Bergamaschi et al. 1997; Meyers 1997; Blair et al. 2004). Accordingly, geochemical studies in heterogeneous sediments frequently quantify sedimentary OM separately for fine- and coarsegrained sediment, as well as for the bulk sediment as a whole.

In addition to organics associated with sediments, the mineralogical and elemental compositions of sediment grains and any inorganic materials sorbed to those particles can also be highly informative in developing a geochemical fingerprint of sediment sources. Sediments transported by a river or stream are expected to be composed of a mixture of sediments derived from various locations and parent materials within that watershed. In addition, a wide range of processes impact the mineralogy and elemental composition of individual sediment grains including biocycling, leaching, and weathering under different moisture, redox, and 
temperature conditions (Buol et al. 1997). As these factors change throughout a drainage basin, the mineralogy and elemental composition of sediments within that basin may also change (e.g., Goodbred and Kuehl 1998). Along with natural variability within a drainage basin, anthropogenic activity may also impact elemental composition of sediments being eroded and transported. For example, alteration of land usage and exposure of soil and sediment to a variety of contaminants could result in a change in the elemental composition or even mineralogy (via dissolution and precipitation) of sediments within a catchment. There are also a variety of sources of contaminants within a catchment including nuclear, mining and industrial wastes, atmospheric and agricultural pollutants, and military activities that can contribute potentially unique elemental and chemical signatures to sediment particles, which can then be utilized to develop a geochemical fingerprint for the region.

\subsection{Sedimentary stable isotope tracers}

In some instances, identification of source material can be achieved by examining specific elemental isotopes existing within the sediment. Two commonly used stable isotopes for distinguishing sediments are carbon and nitrogen. Carbon occurs in a wide variety of forms associated with sediments from organic compounds to inorganic carbonates. Carbon has two stable isotopes, ${ }^{12} \mathrm{C}$ and ${ }^{13} \mathrm{C}$. Over $98 \%$ of carbon occurs as ${ }^{12} \mathrm{C}$ with only approximately $1 \%$ occurring as ${ }^{13} \mathrm{C}$ (Hoefs 2009). Despite the overwhelming abundance of ${ }^{12} \mathrm{C}$, preferential fractionation of the two isotopes can occur through chemical and biological reactions that alter the ratio of ${ }^{13} \mathrm{C} /{ }^{12} \mathrm{C}$, known simply as $\delta^{13} \mathrm{C}$, of different substances. Therefore, the $\delta^{13} \mathrm{C}$ of sediment and the $\mathrm{OM}$ associated with the sediment can often be utilized to help determine the source of material. For example, $\delta^{13} \mathrm{C}$ measurements of $\mathrm{OM}$ can help elucidate the relative abundances of different plant material (i.e., $\mathrm{C} 4$ vs. $\mathrm{C}_{3}$ photosynthesis) in soils and sediments, as well as the presence of marine organics in estuarine and coastal areas (e.g., Goni et al. 1998; Gordon and Goni 2003). Additionally, $\delta^{13} \mathrm{C}$ measurements can be helpful in identifying carbonate rich sediments or detecting the presence of petroleum (Hoefs 2009).

As with carbon, nitrogen has two stable isotopes with $>99 \%$ of nitrogen occurring as ${ }^{14} \mathrm{~N}$ and $<0.5 \%$ in the form of ${ }^{15 N}$. Preferential fractionation of these isotopes in OM occurs in biological processes such as nitrogen fixation, oxidation (or nitrification), and reduction (or denitrification). Nitrogen fractionation also occurs during metamorphism of sediments as 
ammonium is lost during devolatilization (Hoefs 2009). The $\delta^{15 \mathrm{~N}}$ (ratio of ${ }^{15 \mathrm{~N}} /{ }^{14 \mathrm{~N}}$ ) fingerprint of $\mathrm{OM}$ and sedimentary material can also be useful in characterizing sediments and identify their source(s). $\delta^{15} \mathrm{~N}$ measurements are often helpful in distinguishing between agricultural and nonagricultural soils due to the presence of chemical fertilizers and manure or from the possible alteration of the $\delta^{15} \mathrm{~N}$ signature due to frequent tilling (Fox and Papanicolaou 2007). They may also be used to indicate the presence of sewage and help distinguish marine from terrestrial sources of OM (e.g., Rumolo et al. 2011; Gireeshkumar et al. 2013). Inorganic applications of $\delta{ }^{15} \mathrm{~N}$ include identifying the different rock sources of sediments, such as basaltic vs. metamorphic derived-sediment, which can further elucidate the original erosion source of accumulating sediment (Hoefs 2009).

\subsection{Radioisotopes}

Radioisotopic dating is based on measuring the amount of energy released by radioactive decay, or "activity," of specific radioisotopes in sediment. The amount of activity of any given radioisotope in a sediment sample provides valuable information regarding both the source (i.e., marine vs. terrestrial) of the material. In addition, radioisotope activities can be used to quantify both the length of time a particle has either been in suspension or how long since it was deposited. Additionally, once activity has been calculated for multiple samples, the change in activity with increasing depth can be used to determine sediment accumulation rates over time scales of weeks to decades. Several naturally occurring, short-lived radioisotopes that are commonly used to determine sediment sources and/or accumulation rates in accreting regions, including $7 \mathrm{Be},{ }^{234 \mathrm{Th},}{ }^{210} \mathrm{~Pb}$,

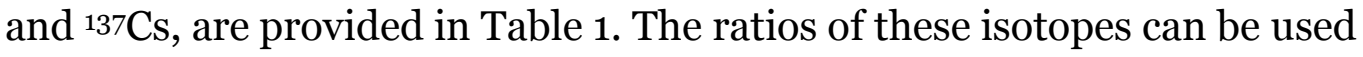
in conjunction with their absolute activities to establish a similar history of particle age and source in suspended and near-surface sediment.

Examples of common isotope ratios are provided in Table 2.

With its short half-life (53.3 days) and highly particle-reactive nature, 7Be is a particularly useful tracer for understanding particle dynamics on short (days-months) timescales. $7 \mathrm{Be}$ is strongly indicative of terrestrial origin for a sediment particle (e.g., Feng 1999a; Mullenbach and Nittrouer 2000; Mullenbach et al. 2004; Wilson et al. 2005). Another radioisotope commonly used in examining particle dynamics on short time scales is ${ }^{234} \mathrm{Th}$. ${ }^{234} \mathrm{Th}$ is the immediate daughter product of the alpha decay of ${ }^{238 \mathrm{U}}$. 
${ }^{238} \mathrm{U}$ is ubiquitous in the geologic cycle, and sediment always has measurable amounts of ${ }^{238} \mathrm{U}$, as well as "supported" ${ }^{234} \mathrm{Th}$.

Table 1. Four of the most commonly used radioisotopes in geochemical fingerprinting.

\begin{tabular}{|l|l|l|l|}
\hline Isotope & Half-Life & Indicates & Applicable Time Scales \\
\hline $234 \mathrm{Th}$ & 24 days & “Fresh" marine & $\begin{array}{l}\text { Days-Weeks (up to } \sim 3 \\
\text { months) }\end{array}$ \\
\hline${ }^{7} \mathrm{Be}$ & 53 days & "Fresh" terrestrial & $\begin{array}{l}\text { Weeks-Months (up to } ~ 6 \\
\text { months) }\end{array}$ \\
\hline${ }^{210 \mathrm{~Pb}}$ & 22 years & Accumulation rates & $\begin{array}{l}\text { Months-Decades (up to } \\
\sim 80 \text { years) }\end{array}$ \\
\hline${ }^{137} \mathrm{Cs}$ & 30 years & $\begin{array}{l}\text { Accumulation rates/Age } \\
\text { of deposit }\end{array}$ & $\begin{array}{l}\text { Years-Decades (up to } ~ 50 \\
\text { years) }\end{array}$ \\
\hline
\end{tabular}

Table 2. The most commonly used radioisotope ratios in the context of geochemical fingerprinting.

\begin{tabular}{|l|l|}
\hline Ratio & Information \\
\hline${ }^{7} \mathrm{Be} /{ }^{234} \mathrm{Th}$ & $\begin{array}{l}\text { Ratio of fresh terrestrial vs. marine suspended/bottom } \\
\text { sediment }\end{array}$ \\
\hline $\begin{array}{l}\text { 7Be/210Pb; } \\
\text { 234Th/210 Pb }\end{array}$ & $\begin{array}{l}\text { Particle age and history (e.g., a suspended sediment sample is } \\
\text { composed of primarily fresh terrestrial sediment vs. older, } \\
\text { resuspended bottom sediment) }\end{array}$ \\
\hline
\end{tabular}

Total $238 \mathrm{U}$ activity, and thus $234 \mathrm{Th}$ activity, is highest when associated with a dissolved phase in the marine water column (e.g., Borole et al. 1982; Toole et al. 1987; Feng et al. 1998). Sediment particles suspended in marine-estuarine environments scavenge this dissolved $234 \mathrm{Th}$ activity which distinguishes them from sediment particles sourced from freshwater environments. Variations in a system's ${ }^{234}$ Th activity can therefore be used to understand short-term particle dynamics between fresh and marine (or estuarine) end-members (e.g., Borole et al. 1982; McKee et al. 1983; Toole et al. 1987; Feng et al. 1998; Feng et al. 1999b; Savoye et al. 2006; Waples et al. 2006).

${ }^{210} \mathrm{~Pb}$ is also produced from the decay of sedimentary ${ }^{238} \mathrm{U}$. However, several daughter isotopes are produced between the initial decay of ${ }^{238} \mathrm{U}$ and the eventual formation of radioactive ${ }^{210} \mathrm{~Pb}$, including the gaseous radioisotope ${ }^{222} \mathrm{Rn}$. As a result, concentrations of ${ }^{210} \mathrm{~Pb}$ are higher in the 
atmosphere than in the water column and higher in the water column than the adjacent seabed. Sediment freshly eroded from the catchment and/or held in suspension in the water column has higher rates of ${ }^{210} \mathrm{~Pb}$ activity than material that has been deposited. With a half-life of $\sim 22$ years, the decay of that excess ${ }^{210} \mathrm{~Pb}$ over time in seabed sediments yields sediment accumulation rates over yearly-decadal time scales (e.g., Appleby and Oldfield 1983; Ritchie and McHenry 1990; Sommerfield 2006; Kirchner 2011). Given that the activity of excess ${ }^{210} \mathrm{~Pb}$ decays with depth, a deeper resuspension event will yield suspended sediment with much lower excess ${ }^{210} \mathrm{~Pb}$ activity than sediments eroded near the seafloor surface or sediments that have been in suspension long enough to sorb excess ${ }^{210} \mathrm{~Pb}$ from the water column. Therefore, variations in the excess activity of ${ }^{210} \mathrm{~Pb}$ have been successfully used to track the source and residence time of coastal sediment (Baskaran et al. 1997; Jweda et al. 2008; Hancock and Caitcheon 2010).

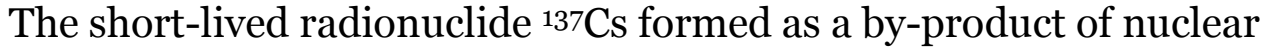
testing and has been used to validate sediment accumulation rates derived from other methods. During the atomic bomb testing era, ${ }^{137 \mathrm{Cs} \text { was }}$ distributed throughout the world via atmospheric fallout. The depth at which the first appearance and/or the 1963 peak is found is used to calibrate the accumulation rate derived from the ${ }^{210} \mathrm{~Pb}$ activity profile (e.g., Sommerfield and Nittrouer 1999; Fuller et al. 1999; Simms et al. 2008). Activities of ${ }^{137 \mathrm{Cs}}$ in surface sediments are also used to track the source, transport, and deposition of terrestrial sediments in coastal systems (e.g., Ritchie and McHenry 1990; Noakes and Jutte 2006).

\subsection{Statistical tools}

When considering methods to geochemically fingerprint sediments, it is important to realize that the physicochemical characteristics rarely exist independently of each other in soils/sediments but are instead spatially and temporally interrelated. The presence of these covariate relationships among sediment geophysical and geochemical properties complicates distinguishing sources with a single defining property, as is commonly attempted. Therefore, the complex nature of sediment's geochemical characteristics makes a geochemical fingerprint better suited to be distinguished by multivariate approaches, where one considers the entire characterization matrix. A combination of PCA, partial least squares Discriminant Analysis (PLS-DA), and soft independent models for classification analogy (SIMCA) can be used to determine if sediments from 
different geographic areas are geochemically distinguishable. In simplistic terms, PCA clusters sediments based on their statistical "similarity". These statistical similarities are calculated as scores for each reduced dimension, defined as a Principal Component (PC). To formally assess the statistical validity of the assigned class memberships for the sediment samples, or groupings defined by PCA, unsupervised classification methods such as SIMCA and PLS-DA can be utilized. SIMCA allows for the classification of samples based on the relative "distance" among the different PCA models built for each group of sediments, thus allowing the sediments to be grouped with geochemically similar fingerprints. PLS-DA is performed to sharpen the separation between groups of observations by analyzing and rotating PCA components such that a maximum separation among classes (i.e., sediment groupings) is obtained. PLS-DA can further be used to understand which geochemical parameters carry the class-separating information. This information can then be used to infer information about geochemically indistinguishable sediments (e.g., likely sediment sources). The following paragraphs are an in-depth description of the analyses that can be applied to sediment systems.

PCA quantifies inherent (and often unseen) relationships existing in samples based on the existing covariance among variables (Esbensen 2010). Loadings in PCA are defined as the correlation ( $r$ ) between two variables (vectors), $x$ and $y$ as

$$
r(x, y)=\frac{\operatorname{Cov}(x, y)}{S_{x} S_{y}}
$$

where si $=$ standard deviation of the variables. Here, the variables represent the geochemical characterization data used to describe each sample. If projected in reduced space, based on the direction of the principal axis, then the relationship between the variable covariance and angle of the vectors separating $x$ and $y$ is

$$
r(x, y)=\cos \theta=\frac{x^{T} y}{\|x\|\|y\|}
$$

where, $x T$ represents the transpose of variable $x$ and $\|i\|$ represents the mean-centered variables. Thus, the correlation of variables $x$ and $y$ to the PCs as well as to each other is indicated graphically by their respective angles to the principal axes. For example, if the angle between the vectors (plotted in reduced space) describing variable $x$ and the principal axis (PC- 
1) is close to zero, then variable $x$ is well described by PC-1 (because cos 0 $=1$ ). Similarly, if the angle between variable $x$ and PC-1 is close to $180^{\circ}$, then variable $x$ is considered negatively correlated to PC-1 (because $\left.\cos \left(180^{\circ}\right)=-1\right)$. Also, if the angle between two variables is close to $180^{\circ}$, the two variables $x$ and $y$ are considered anticorrelated. In short, if the variables are close together geometrically, they are correlated.

By quantifying the correlations among all of the variables in a data matrix, PCA can essentially reduce the dimensionality of large, multivariable datasets to small subsets of orthogonal PCs. The advantage of this technique is that it elucidates latent structure in multivariate data matrices that may not be readily apparent from a univariate comparison of the absolute values within the characterization data. Furthermore, these relationships extend to the samples by which the variables are described through the decomposition of the raw data matrix $(X)$ as indicated by general centered PCA model (Esbensen 2010):

$$
X=\boldsymbol{T} \boldsymbol{P}^{T}+E
$$

where, $T$ = Score matrix, $P^{T}=$ accompanying loading matrix (transposed), and $E=$ the error (nonstructural) or residual matrix in the data isolated from the analysis. Thus, the PC model represents the matrix product of $T P^{T}$.

These relationships are important when comparing the score and loading plots. These two plots are considered complementary and most revealing when the positions of the objects and variables are studied together. By mentally superimposing the score and loading plot, the same rules described above apply for matching correlated variables with objects. Thus, PCA is a powerful approach that has proven particularly effective in finding relationships among complex soil and sediment data (e.g., Chappell et al. 2011; Chappell et al. 2013; Mathangwane et al. 2008; Steevens et al. 2011). For example, Chappell et al. (2013) used PCA to geochemically distinguish fly ash samples from background soils and sediments (Figure 1) in order to detect mixing of spilled fly ash at the Tennessee Valley Authority Kingston Fossil plant with the Emory River sediment.

In Figure 1, PCA grouped the samples based on (a) whether they contained spilled fly ash (PC-1) and (b) whether samples were collected from the 
river or from upland sites (PC-2). Strongly correlated relationships among samples and variables are indicated by position relative to the primary axis (PC-1) and proximity of data points projected on the plots. Samples occurring on the right side (i.e., quadrants I and II) of both the score and loading plot in Figure 1 are those containing higher concentrations of elements. In other words, samples positively loaded in PC-1 represent those with high elemental concentrations and are positioned in the score plot similar to the metal variables represented in the loading plot. Note that almost all of the reference soil and sediment samples are negatively or anticorrelated because they are negatively loaded in PC-1. Additional distinction among the reference samples is seen in PC-2 with sediment samples loading negatively while soil samples load positively. Thus, the PCA shows that the reference soils are geochemically anticorrelated to the reference sediment samples and further suggests that the higher elemental concentrations found in spill site samples are a result of the soil being scoured from the landscape during the collapse of the coal-ash pile, before deposition. 
Figure 1. Plots showing the results of an optimized PCA model containing two PCs explaining $94 \%$ of the variance in the data. The score plot (upper) describes the relationships among the samples while the lower plot (loading) describes the relationships among the variables.

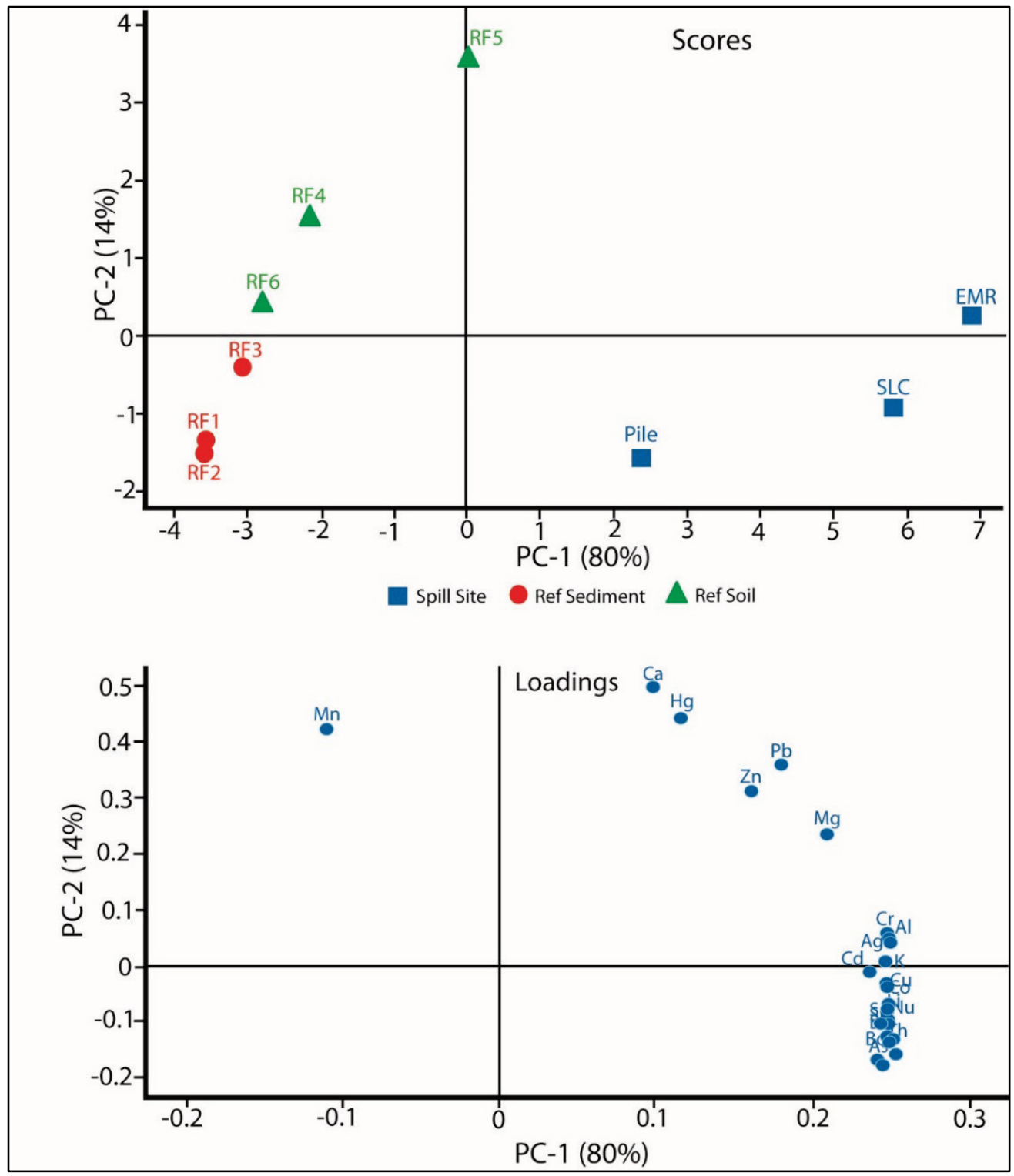




\section{Example Applications}

The examples below are not meant to represent an exhaustive list of the potential uses of geochemical markers. Rather, they illustrate some of the more common geochemical fingerprinting research that is also USACE relevant.

\subsection{Sediment budgets via geochemical markers}

Repetitive dredging to maintain navigation channels, harbors, and ports comprises a significant component of USACE's yearly budget. Sediment accumulation rates in navigable regions may potentially be higher than accumulation rates in similar, natural systems, as the engineering design used to minimize wave energy and protect vessels and coastal infrastructure may actually enhance sediment deposition and accretion. Future costs of maintenance dredging are expected to continue to increase due to increasing sediment loads in some regions as well as more costly environmental mitigation post-dredging. Despite these substantial costs, little to no research is currently conducted by USACE to geochemically identify the source(s) of infilling sediment and the processes by which those sediments are being delivered to navigable regions.

A complete understanding of the rate at which sediment accumulates in navigable regions, as well as pinpointing the source(s) of infilling sediment, requires a quantitative understanding of the entire sedimentary system, from the sediment's source to its ultimate sink. A key component of this is an accurate sediment budget, which takes into account the total sediment inputs and outputs for a given region over time. In principle, deriving a sediment budget for any given region is simple: (1) quantify the amount of sediment being transported into the region and then (2) determine if that sediment accumulated within the region, where it accumulated, and the rate at which it was deposited over the time frame of interest. While techniques for measuring and predicting riverine sediment loads as a function of discharge are relatively straightforward, determining the ultimate fate of sediment is significantly more complicated. Repeated bathymetric surveys provide a rapid and relatively inexpensive way to quantify erosion and accretion in a region of interest, with differences in elevation between repeated surveys being used to estimate sediment transport and accumulation. Estimates of the total volume removed during dredging operations also yield insight as to how much sediment 
accumulated between individual dredging events. Unfortunately, these methodologies are limited in that (1) they provide instantaneous measurements, or snapshots, of bathymetric change, which might not be indicative of long-term erosion or accretion patterns; (2) some of the measured change between bathymetric surveys is frequently related to variations in the precision and accuracy of the survey methods employed, and dredging volumes likewise suffer from similar methodology inaccuracies; and (3) even if the bathymetric or volume change measured is an accurate representation of the overall change in a system, it provides no information regarding the source of the infilling sediment and only a limited sense of the time over which the deposition occurred.

The use of sediment geochemical fingerprints potentially provides a much more accurate, detailed, and quantitative method of establishing a sediment budget for a region. In this method, profiles of radioactivity, as preserved within sediment cores collected throughout the region in question, unequivocally identify regions of sediment accumulation at a range of time scales (Appleby and Oldfield 1983; Ritchie and McHenry 1990; Sommerfield 2006; Kirchner 2011 and references therein). Specifically, activity profiles and inventories of $7 \mathrm{Be},{ }^{234 \mathrm{Th}}$, and ${ }^{210} \mathrm{~Pb}$,

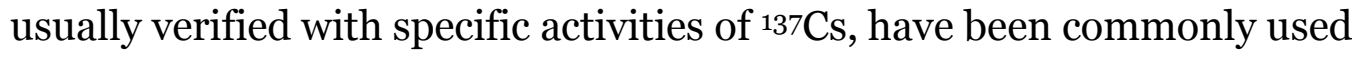
to estimate short-term to long-term sediment budgets (weeks to $\sim 100$ years) in a wide range of coastal environments, including marshes (e.g., Sharma et al. 1987; Zwolsman et al. 1993), estuaries (e.g., Ravichandran et al. 1995; Dellapenna et al. 1998; Patchineelam 1999; Rubio et al. 2003), and harbors, bays, and fjords (e.g., Krishnáswami et al. 1980; Sugai 1990; Fuller et al. 1999; Pfitzner et al. 2004). When coupled with measurements of variations in elemental composition, mineralogy, and stable isotopes, the result is a detailed sediment budget that includes the source(s) of the sediment accumulating and the rate at which sediments are accumulating. These data can be used to significantly improve predictions of not only how much sediment has or will accumulate in a given navigable waterway over a period of time but from where the accumulating sediment is sourced.

Geochemical markers can also be used to discern the source(s) of accumulating sediments. Many of the markers described in the methods section of this report provide useful "source" identification. For example, oceanic-sourced sediment can be discerned from terrestrial-sourced sediment via (1) mineralogy (i.e., sediment sourced from the erosion of 
calcite reefs offshore vs. the erosion of terrestrial volcanic rock); (2) radioisotopes (presence of excess ${ }^{234} \mathrm{Th}$ ); and (3) TOC and TN ratios (nitrogen-rich marine vs. carbon-rich terrestrial). Within a terrestrial watershed, sediment sourced from different regions of the catchment basin can be sourced via (1) mineralogy (i.e., a region of dominantly limestone vs. a region of dominantly basalt); (2) TOC and TN ratios (agricultural soils vs. forest soils); (3) trace elements or toxins (i.e., from the vicinity of a known pollutant, such as poorly contained mining slag). If the source of accumulating sediment is from a dredge-induced plume, this sediment can also be discerned from naturally accumulating sediment (described in more detail in the following sections). The actual markers used will depend on the specific project needs and environment.

\subsection{Constraining dredging impacts}

Several hundred million cubic yards of material are removed from navigational regions in any given year in order to maintain the needs of commercial, national defense, and recreational users of the nation's waterways. In addition to deepening channels and harbors and providing vast amounts of dredged sediment that can be used for coastal rehabilitation projects (e.g., Yozzo et al. 2004), dredging resuspends significant quantities of bottom sediment. Once resuspended, this sediment can be transported significant distances downstream before it settles out of suspension, potentially impacting ecosystems far downstream from the dredge or disposal site (e.g., Taylor and Saloman 1968; Sustar et al. 1976; Johnston 1981; Nichols et al. 1990; Nayar et al. 2007). Dredge-related increases in suspended sediment have been shown to stress local biota through increased turbidity (e.g., Everhart and Duchrow 1970; Johnston 1981; Newell et al. 1998; Lewis et al. 2001), reduced food availability or feeding effectiveness (e.g., Bouma 1976), and negatively impact natural physiochemical processes (e.g., Wirth et al. 1996; Newell et al. 1998). In addition, toxic material associated with resuspended dredged sediment may be re-released into the system, providing additional stress to the ecosystem (e.g., Palmer and Gross 1979; Wirth et al. 1996; Goh and Chou 1997; Nayar et al. 2003).

Techniques for tracking sediment suspended via dredging activities have greatly expanded in the last several decades. Methods have advanced from water column total suspended solids (TSS) and seabed sampling to include optical, acoustic, and remote sensing techniques. Commonly accepted methodologies include but are not limited to (1) observing the deposition 
of "new" sediment on the seabed in the vicinity of the dredge site either directly, via seabed sampling (e.g., Nichols et al. 1990; Black and Parry 1999; Hitchcock and Bell 2004; Kim and Lim 2009) or indirectly, via sidescan sonar and/or bathymetric changes (e.g., Hitchcock and Bell 2004; Smith et al. 2008); (2) water column sampling prior to and throughout dredging (e.g., Nichols et al. 1990; Pranovi et al. 2004; Smith et al. 2008); (3) optical monitoring via optical backscatter (OBS) measurements or other optical methods (e.g., Downing et al. 1981; Downing 1983; Hamilton et al. 1998; Smith et al. 2008); (4) acoustic tracking of dredged sediment plumes throughout the water column (e.g., Land and Bray 2000; Reine et al. 2002; Gartner 2004; Hitchcock and Bell 2004); and (5) remote sensing (i.e., Landsat TM and MODIS) of dredging vessels and associated turbidity plumes (e.g., Jorgensen and Edelvang 2000; Wu et al. 2007). Although a detailed comparison of the effectiveness of these methods is beyond the scope of this document, note that none of these methodologies provide any quantitative data on the origin of the sediment they are tracking. Instead, while several methods can use the change in suspended sediment concentrations predredging vs. during dredging to identify and initially track dredge-induced plumes, once the dredge plume concentrations reach background levels, there is no reliable way to distinguish any remaining suspended dredged material from the ambient suspended sediment (Figure 2). Accordingly, deleterious effects from increased turbidity or seafloor accumulation observed downstream of a dredging operation are often considered to be dredge related and the sole responsibility of USACE to remediate.

Figure 2. Depiction of ambient suspended and bottom sediment from oceanic and riverine sources (left panel). Right panel shows the inclusion of dredge-suspended sediment. Dashed red box indicates the likely limitation of dredge plume detection without the use of geochemical markers.
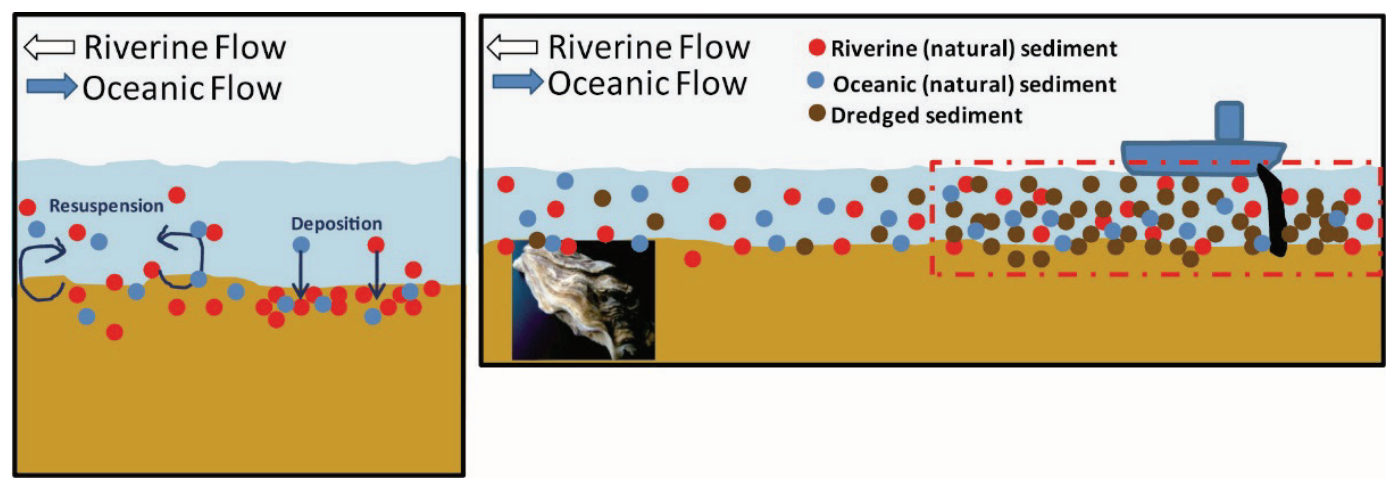

Ratios of naturally occurring radioisotopes are commonly used to distinguish old, resuspended material from fresh sediment, both in 
suspension and in accumulating regions (e.g., Feng et al. 1998; Feng et al. 1999a,b; Matisoff et al. 2005; Whiting et al. 2005). Specifically, sediment inventories and ratios of $7 \mathrm{Be}$ and $234 \mathrm{Th}$ (Volger et al. 1996; Feng et al. 1999a,b), 7Be and ${ }^{210} \mathrm{~Pb}$ (Baskaran et al. 1997; Wilson et al. 2003; Matisoff et al. 2005; Wilson et al. 2007; Jweda et al. 2008; Wilson et al. 2008; Peterson 2009; Hancock and Caitcheon 2010; Feng et al. 2010; Saari et al. 2010), ${ }^{210} \mathrm{~Pb}$ and ${ }^{234} \mathrm{Th}$ (Saari et al. 2010), and $7 \mathrm{Be}$ and ${ }^{137 \mathrm{Cs}}$ (Noakes and Jutte 2006) have been used to distinguish fresh suspended sediment from older, resuspended material, including that suspended during dredging. In addition to radioisotopes, it is not difficult to imagine other geochemical signatures being helpful to track dredge plumes. It is not unusual for dredged material from an industrial port/harbor to contain some sort of contamination. This contamination signal could then potentially be used to identify and track resuspended sediments from the dredging operation, especially if these sediments are thought to travel a significant distance and deposit in an environment different from which they originated. Therefore, in the right environment and with proper conditions, this geochemical fingerprinting methodology could be successful in identifying and tracking suspended, and eventually deposited, dredge-resuspended sediment.

\subsection{Improved placement monitoring}

One of the more common ways USACE modifies the coastal landscape is through the creation of dredge disposal sites, both terrestrial and aqueous, and the deliberate placement of sediment on a beach or in the nearshore to reduce or temporarily cease coastal erosion. In all deliberate placement efforts, the morphology of the deposit is regularly monitored, usually by frequent bathymetric or lidar surveying. When sediment is transported slowly from the placement, however, discerning its ultimate sink may prove to be more of a challenge because the downstream volume or elevation change caused by the transported placement material is too small to be mapped with traditional methods. Geochemical fingerprinting can be used to track the movement of placed sediment at a much higher resolution (both temporally as well as spatially) than traditional methods.

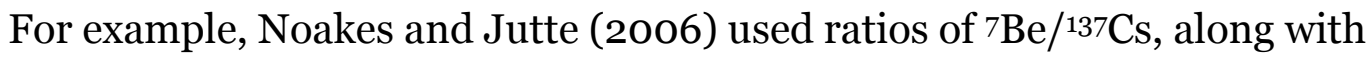
variations in sediment grain size, to track the previously unmapped transport and accumulation of sediment offshore from a dredge disposal site to a coral reef. Theiler et al (1999) tracked the offshore movement of sand from nourished beaches along the North Carolina-South Carolina border using variations in grain size and carbonate mineralogy and 
chemistry. Both of the cited studies were able to track the sediment at a much higher spatial and temporal resolution than traditional volumechange studies.

\subsection{Sediment transport post dam removal}

According to the USACE National Inventory of Dams (NID), there are more than 80,000 dams located within the United States (http://nid.usace.army.mil/cm apex/f?p=838:5:0::NO). The majority of these dams were constructed prior to 1970. As aging and maintenance costs for many of the nation's dams have increased over the last few decades, so has awareness of adverse effects of dams on the physical, chemical and biological characteristics of rivers (Hart et al. 2002). As a result, the viability of dam removal as a means of stream restoration has grown in popularity in recent years (Ahearn and Dahlgren 2005). While dam removal can be beneficial to long-term stream restoration goals, there are also short-term environmental responses, such as increased mobilization of reservoir bottom sediments, that need to be better understood.

A large amount of sediments transported by rivers and streams is deposited and becomes trapped in the reservoirs created by dams. With the removal of dams, these bottom sediments can be transported downstream. Although factors such as channel slope, flow magnitude, and sediment type impact the rate and quantity of sediment that becomes available for transport, an overall increase in sediment load can be expected following drawdown until a new equilibrium in channel morphology, floodplains, and riparian vegetation can be established in the former impoundment (Hart et al. 2002). The transport of these sediments can have significant impacts on water quality and ecosystems downstream. The majority of nutrients in impounded areas are stored in the benthos (Perrin et al. 2000; Stanley and Doyle 2003; Ahearn et al. 2005). The exposure of these sediments as a result of drawdown results in multiple biogeochemical reactions that can have impacts on nutrient levels in both the sediment and water column (Ahearn and Dahlgren 2005). This can be a concern if the exposure and transport of reservoir sediments results in the Total Maximum Daily Limits (TMDLs) for nutrients being exceeded following dam removal. Additionally, dam removal can also result in increased distribution of contaminants downstream. Contaminants such as heavy metals, polychlorinated biphenyls (PCBs), and polycyclic aromatic hydrocarbons (PAHs) are preferentially adsorbed to fine 
sediments. Deposition of these sediments occurs in low-energy environments such as reservoirs. Therefore, reservoirs that receive water and sediment from basins with significant industrial and agricultural activity may contain fine sediments with elevated levels of contaminants. The movement of these materials following dam removal can impact sensitive ecosystems and communities downstream of the reservoir.

Along with nutrients and contaminants that are associated with sediment, the sediment itself can also impact ecosystems and environments downstream of dam removal projects. An increase in fine sediment transport following dam removal can alter bed grain size and water column turbidity. These factors are critical to benthic communities and can determine the species of plants and animals that can survive in an area. For these reasons it is important to monitor sediment dynamics in a system following dam removal and to understand how the system is responding to that alteration.

Geochemical fingerprinting can be an effective tool in identifying and distinguishing sediments that originated from a reservoir prior to dam removal from other fluvial sediments. The deposition and burial of sediment within impoundments created by dams allow for those materials to remain in place for extended periods of time. This longer residence time allows reservoir sediments to "age" in place when compared to those sediments that are actively transported down river. As previously described, radioisotopes can be utilize to determine the age of sediments to some extent. Additionally, the presence and concentration of any contaminants and nutrients that can be associated with reservoir sediments could also be used as identifying markers. If defining markers such as these can be identified that distinguish reservoir sediments from other fluvial sediments, then it would be possible to map out areas most impacted by reservoir sediments based on the presence or absence of these geochemical markers.

\subsection{Offshore fate of terrestrial sediment}

The offshore transport and accumulation of terrestrial sediment can have potentially deleterious effects on coastal ecosystems. Increased sediment loads resulting from the transport of dredge plumes into coastal regions, or from resuspension from offshore disposal sites, have been known to impact sensitive nearshore reef systems by reducing growth, diversity, metabolism, and fecundity (e.g., Rhoads et al. 1978; Guzman and Holst 
1993; Riegl and Branch 1995; Telenicki and Goldberg 1995; Gilmore 1999; Miller and Cruise 1995; Noakes and Jutte 2006) and potentially also contaminate sensitive larval nursery regions (e.g., van den Hurk et al. 1997). Given that the resuspension process may release sediment-sorbed contaminants when a dredge resuspends the contaminated material (e.g., Johnston 1981; van den Hurk et al. 1997; Nayar et al. 2003; Eggleton and Thomas 2004 and references therein), it is critical that dredge-suspended sediments are geochemically identified, distinguished where possible from nondredge-sourced suspended sediment, and tracked to more fully mitigate any deleterious effects they specifically may cause during subsequent transport and deposition. Several other processes can resuspend sediments that can then be transported to sensitive regions, including natural processes (e.g., storm and tidal scour, flood events) as well as other anthropogenic processes (e.g., trawling and vessel wake scour). Despite this, when increased sediment loading is noted offshore of a region dredged or otherwise modified or maintained by the Corps, the Corps is generally considered to be the culprit and solely responsible for mitigation of the impacts the increased sediment loads are causing, even without any supporting geochemical evidence.

Geochemical fingerprints are key for identifying the actual source of increased suspended and accumulating sediment loads. Specifically, Noakes and Jutte (2006) successfully utilized a combination of sediment traps and radioisotope ratios to distinguish natural riverine-sourced vs. dredge-sourced sediment transported offshore from Charleston Harbor onto hard bottom reef habitat. Their results suggested much of the sediment accumulating on the reefs was tidally transported (i.e., not sourced from density-driven dredge plumes), though further geochemical work was needed to fully quantify the relative percentages of dredge vs. natural-sourced sediment in the large region. More recently, Guerra et al. (2009) used a suite of geochemical markers to determine that sediment resuspended by dredging activities in a northern Adriatic coastal lagoon did not adversely affect the environmental quality of the lagoon. The additional, quantitative information yielded by a geochemical study may serve to reduce or even limit the Corps' responsibility when terrestrial sediment that is measured offshore of harbors, estuaries, or bays that are actively modified by Corps' activities is proved not to be sourced by those activities. They may also serve to discern the pathway(s) of sediment transport from the source(s) to the offshore sink. 


\subsection{Military applications}

Contamination of the local ecosystem surrounding military installations, both coastal and inland, is a constant concern. Sources of potential contamination can vary widely, from firing ranges and ordinance storage/disposal/production facilities to fuel depots. Unfortunately, the potential transport of contaminated sediment downstream from these facilities has to date been poorly quantified, with only a few exceptions. Accordingly, when contaminated sediments are found downstream of a military facility, the natural assumption is that the sediment is sourced from the facility or base, and thus the DoD is responsible for all related remediation. Geochemical fingerprints can be used to discern the source(s) of the contaminated sediments, as long as there is geochemical variation in the watershed as a whole. For example, PAHs are measured at similar concentrations in the relatively pristine York River estuary as those measured in the larger, and more impacted, Chesapeake Bay (Countway et al. 2007). Recent research by Countway et al. (2003, 2007) quantified the source(s) of PAHs in the York River and determined if they were potentially related to contamination from either a paper processing mill near the head of the estuary ( $50 \mathrm{~km}$ upstream of the mouth) or Cheatham Annex, a nuclear weapon storage facility located farther downstream ( $\sim 15 \mathrm{~km}$ upstream of the mouth). PCA revealed that PAHs in the estuary were classified into three groups: volatile, soot-associated, and perylene. All three were found to be derived from natural sources (i.e., either plankton derived or terrestrial/vascular plant material derived) and were not sourced from either facility. Studies such as these illustrate that geochemical fingerprints provide a robust and quantitative way of discerning if contaminated sediment is sourced from military facilities. 


\section{Site Selection Criteria}

Despite the potential value in using geochemical fingerprints to identify the different sources of sediment accumulating within a region, a broad acceptance of the methodology is hampered by a lack of a standard, systemic methodology (e.g., Collins et al. 1997; Collins and Walling 2002; Davis and Fox 2009). Because every sediment system is different in terms of geographic location (i.e., terrestrial, marine, or mixed), catchment geology, and land-use practices, no single suite of geochemical tools is appropriate for use at every potential site. In addition, the potential sediment sources need to be distinguishable from the area of concern. Accordingly, the following characteristics should be considered when determining whether a specific site is a viable candidate for geochemical fingerprinting.

\subsection{Historical geochemical data}

Most districts involved in sediment management have a data archive of geochemical data that can provide invaluable location information for a geochemical study. For example, a district may routinely quantify the grain size distribution and percent toxic metals for accumulating harbor sediments prior to routine dredging as part of their overall mission. These data can be reanalyzed to determine not only a site's suitability for geochemical fingerprinting but might also provide preliminary insight into the number and location of potential sediment sources and sinks.

\subsection{Catchment geology}

The geological makeup of a catchment is the ultimate source of the mineralogical fingerprint of a site. Determining the source of sediment in an accumulating region can be done via variations in mineralogy if variations in the geology of the eroding material (such as granitic bedrock vs. limestone) can be quantified. Variations in geology are not limited to terrestrial locations; an accumulating region where the terrestrial end member is volcanic, compared to a coral oceanic end member, can also be distinguished via mineralogy.

\subsection{Catchment land use}

The land-use patterns for a catchment can provide a significant degree of insight as to the source(s) of accumulating sediment. With regards to 
mineralogy and/or trace metals, toxic sediment, such as fly ash, being discharged from part of the catchment could be used to fingerprint sediment accumulating from that region of the catchment. With regards to stable isotopes and radioisotopes, sediments sourced from the erosion of heavily industrialized regions have different isotopic signatures than do sediments sourced from more residential, agricultural, or even natural regions.

\subsection{Variations in organic material}

Although the isotopic signature and composition of organic material sorbed to sediment particles can vary from one catchment to another in a terrestrial setting, a region that has potential terrestrial and oceanic end members will likely have dramatic variations in sedimentary-associated organic composition.

\subsection{Radioisotope availability}

Naturally occurring radioisotopes are not equally distributed spatially or temporally. Using excess ${ }^{234} \mathrm{Th}$ to identify marine and/or short-lived sedimentation requires an oceanic (or very large lacustrine) end member. Excess ${ }^{210} \mathrm{~Pb}$, while more ubiquitous, is not applicable in regions with little rainfall and/or incredibly high suspended sediment yield. Variations in $7 \mathrm{Be}$ activity are limited to the latitudes where $7 \mathrm{Be}$ is atmospherically concentrated (usually below $\sim 50^{\circ}$ latitude), and its presence is temporally variable due to known atmospheric circulation patterns (typically early spring to summer). 


\section{Guidance for Use}

It is unlikely that every site that could benefit from geochemical fingerprinting of accumulating sediment will meet all of the above-listed criteria. Nor is it possible to set a minimum number of criteria that any site should meet; for instance, a site characterized by sedimentation from both open ocean and terrestrial sources but where the catchment geology or land use does not differ at either end member, may still benefit from a geochemical analysis. Not every site will have an extensive historical dataset, either. In addition, the nature of the query is also critical in determining the usefulness of a geochemical analysis. For instance, if the timing of sediment accumulation in a navigable region is under question, radioisotope analysis might provide useful insight but only if the grain size and/or latitude of the site are favorable for analysis. Accordingly, each potential site should be considered independently.

The following outline presents a simple checklist for determining if a site is a candidate for geochemical fingerprinting and a rough outline for the general steps that will be followed during a typical study. Not all sites will have an abundance of previously collected sediment or survey data for initial analysis. Additional data, such as bathymetric, lidar, or geophysical surveying may be required to more quantitatively map a source or sink deposit at a site, and this potential need will be evaluated on a site-by-site basis. The actual geochemical markers to be used, and thus the length of time and total cost that new collection and analyses will take to perform, will also be determined on a site-by-site basis. The general checklist and subsequent study steps, however, will be relatively consistent for every site considered.

1. Determination of site suitability

a. Evaluation made via charts, maps, and/or other sources of potential sources and transport pathways in the area in question.

i. Example: The catchment related to an infilling harbor is mapped on Google Earth, bathymetric charts, geologic maps, and surface soil maps to determine potential geochemically distinct sediment sources and transport pathways.

ii. Example: Primary literature is scoured for references pertaining to sediment dynamics, especially 
geochemically derived sediment budgets, for the region in question.

b. Evaluation made of existing sediment and/or survey data.

i. Example: The district provides all historical dredging volumes, grain size data, and heavy metal concentrations for the harbor for preliminary PCA analyses. Alternatively, historical data might be available through other sources, such as contractors, consultants, or scientific literature.

ii. Example: When available, archived sediment samples can be reanalyzed to perform geochemical studies, not generally included in routine analyses, for preliminary fingerprinting analyses.

2. Study components

a. Site visit (if possible) is arranged to determine sampling access to all potential sources and pathways and to finalize the type of geochemical markers to be quantified. Suspected sediment sources and pathways are sampled at this time.

b. Field efforts are planned and sediment collected.

i. Multiple site visits may be planned if a seasonal impact on processes is suspected.

ii. If necessary, cores will be collected to determine accumulation rates during the first field effort.

c. Analyses are run, and data input into PCA models.

i. Results from sample analyses will be compiled into a database for PCA.

ii. Multiple PCAs will likely be run to fully discern all the potential sediment sources.

iii. Additional field efforts might be required if PCAs indicate a source was insufficiently sampled.

Final report/publication is prepared. In-person brief, when possible, is provided to the District. 


\section{Summary}

Although geochemical markers have been used by the greater scientific community to discern the sources, sinks, and transport processes of sediment in aqueous environments for decades, the USACE has been slow to adopt the methodology as part of its regular sediment research and monitoring plans. Geochemical fingerprinting can be a useful tool for sediment management that is directly relevant to the Corps' overall mission. To be used effectively, a prior understanding of the system and its likely sources and sinks of sediment is required. Many applicable sites, however, hold a wealth of such data collected during regular sediment and/or dredge monitoring activities. Although the method will not be applicable in every site for every application, as long as there is some heterogeneity between sediment types and sources, then geochemical fingerprinting could be a possible technique that greatly improves the Corps' ability to effectively and economically manage sediment. 


\section{References}

Ahearn, D. S. and R. A. Dahlgren. 2005. Sediment and nutrient dynamics following a lowhead dam removal at Murphy Creek, California. Limnology and Oceanography 50(6): 1752-1762.

Ahearn, D. S., R. W. Sheibley, and R. A. Dahlgren. 2005. Effects of river regulation on water quality in the lower Mokelumne River, California. River Research and Applications 21(6): 651-670.

Appleby, P.G., and F. Oldfield. 1983. The assessment of ${ }^{210} \mathrm{~Pb}$ data from sites with varying sediment accumulation rates. Hydrobiologia 103(1): 29-35.

Baskaran, M., M. Ravichandran, and T. S. Bianchi. 1997. Cycling of $7 \mathrm{Be}$ and ${ }^{210} \mathrm{~Pb}$ in a high DOC, shallow, turbid estuary of south-east Texas. Estuarine, Coastal and Shelf Science 45(2): 165-176.

Bergamaschi, B. A., E. Tsamakis, R. G. Keil, T. I. Eglinton, D. B. Montlucon, and J. I. Hedges. 1997. The effect of grain size and surface area on organic matter, lignin and carbohydrate concentration, and molecular compositions in Peru Margin sediments. Geochimica et Cosmochimica Acta 61(6): 1247-1260.

Black, K. P., and G. D. Parry. 1999. Entrainment, dispersal and settlement of scallop dredge sediment plumes: Field measurements and numerical modeling. Canadian Journal of Fish and Aquatic Sciences 56(12): 2271-2281.

Blair, N. E., E. L. Leithold, and R. C. Aller. 2004. From bedrock to burial: The evolution of particulate organic carbon across coupled watershed-continental margin systems. Marine Chemistry 92(1-4): 141-156.

Bordovskiy, O. K. 1965. Transformation of organic matter in bottom sediments and its early diagenesis (April 1965). Marine Geology 3(1-2): 83-114.

Borole, D. V., S. Krisnáswami, and B. L. K. Somayájulu. 1982. Uranium isotopes in rivers, estuaries and adjacent coastal sediments of western India: Their weathering, transportation and oceanic budget. Geochimica et Cosmochimica Acta 46(2): $125^{-137 .}$

Bouma, A. H., ed. 1976. Shelf dredging and its influence on Gulf Coast environments. Houston: Gulf Publishing Company.

Buol, S. W., F. D. Hole, R. J. McCracken, and R. J. Southard. 1997. Soil genesis and classification, $4^{\text {th }}$ Edition. Iowa State University Press: John Wiley and Sons.

Chappell, M. A., C. L. Price, B. E. Porter, B. A. Pettway, and R. D. George. 2011. Differential kinetics and temperature dependence of abiotic and biotic processes controlling the environmental fate of TNT in simulated marine systems. Marine Pollution Bulletin 62(8): 1736-1743. 
Chappell, M. A., J. M. Seiter, A. J. Bednar, C. L. Price, D. Averett, B. Lafferty, R. Tappero, J. S. Stanley, A. J. Kennedy, J. A. Steevens, Z. Pingheng, E. Morikawa, M. Merchan, and A. Roy. 2013. Stability of solid-phase selenium species in dredged fly ash after prolonged submersion in a natural river system. Chemosphere 95: 174-181.

Collins, A. L., D. E. Walling, and G. J. L. Leeks. 1997. Sediment sources in the Upper Severn catchment: A fingerprinting approach. Hydro. and Earth Sys. Sci. 1(3): 509-521.

Collins, A. L., and D. E. Walling. 2002. Selecting fingerprint properties for discriminating potential suspended sediment sources in river basins. Journal of Hydrology 261(1): 218-244.

Countway, R. E., E. A. Canuel, and R. M. Dickhudt. 2007. Sources of particulate organic matter in surface waters of the York River, VA, estuary. Organic Geochemistry 38(3): 365-379.

Countway, R. E., R. M. Dickhudt, and E. A. Canuel. 2003. Polycyclic aromatic hydrocarbon (PAH) distributions and associations with organic matter in surface waters of the York River, VA, estuary. Organic Geochemistry 34(2): 209-224.

Davis, C. M., and J. F. Fox. 2009. Sediment fingerprinting: Review of the method and future improvements for allocating nonpoint source pollution. Journal of Environmental Engineering 135(7): 490-504.

Dellapenna, T. M., S. A. Kuehl, and L. C. Schaffner. 1998. Sea-bed mixing and particle residence times in biologically and physically dominated estuarine systems: A comparison of Lower Chesapeake Bay and the York River subestuary. Estuarine, Coastal and Shelf Science 46:(6) 777-795.

Downing, J. P., R. W. Sternberg, and C. B. Lister. 1981. New instrumentation for the investigation of sediment suspension processes in the shallow marine environment. Marine Geology 42(1-4): 19-34.

Downing, J. P. 1983. An optical instrument for monitoring suspended particulates in ocean and laboratory. In OCEANS '83 Conference Proceedings, San Francisco, CA, IEEE and MTS, 199-202.

Eggleton, J., and K. V. Thomas. 2004. A review of factors affecting the release and bioavailability of contaminants during sediment disturbance events. Environment International 30(7): 973-980.

Esbensen, K. H. 2010. Multivariate data analysis - in practice : An introduction to multivariate data analysis and experimental design, $5^{\text {th }}$ Edition. Norway: CAMO Software AS.

Everhart, W. H., and R. M. Duchrow. 1970. Effects of suspended sediment on aquatic environments. NTIS U.S. Department of Commerce, PB-196-641.

Feng, H., J. K. Cochran, D. J. Hirschberg, and R. E. Wilson. 1998. Small-scale spatial variations of natural radionuclide and trace metal distributions in sediments from the Hudson River Estuary. Estuaries 21(2): 236-280. 
Feng, H., J. K. Cochran, and D. J. Hirschberg. 1999a. ${ }^{234}$ Th and 7 Be as tracers for the transport and dynamics of suspended particles in a partially mixed estuary. Geochimica et Cosmochimica Acta 63(17): 2487-2505.

Feng, H., J. K. Cochran, and D. J. Hirschberg. 1999b. ${ }^{234}$ Th and $7 \mathrm{Be}$ as tracers for the sources of particles to the turbidity maximum of the Hudson River estuary. Estuarine, Coastal and Shelf Science 49(5): 629-645.

Feng, H., W. Zhang, L. Jia, M. P. Weinstein, Q. Zhang, D. Yuan, J. Tao, and L. Yu. 2010. Short- and long-term sediment transport in western Bohai Bay and coastal areas. Chinese Journal of Oceanography and Limnology 28(3): 583-592.

Forrest, B. M., P. A. Gillespie, C. D. Cornelisen, and K. M. Rogers. 2007. Multiple indicators reveal river plume influence on sediments and benthos in a New Zealand coastal embayment. New Zealand Journal of Marine and Freshwater Research 41: 13-24.

Fox, J. F., and A. N. Papanicolaou. 2007. The use of carbon and nitrogen isotopes to study watershed erosion processes. Journal of the American Water Resources Association 43(4): 1047-1064.

Fuller, C. C., A. van Geen, M. Baskaran, and R. Anima. 1999. Sediment chronology in San Francisco Bay, California, defined by ${ }^{210} \mathrm{~Pb},{ }^{234 \mathrm{Th}}, 13^{7} \mathrm{Cs}$, and ${ }^{239},{ }^{240} \mathrm{Pu}$. Marine Chemistry 64(1-2): 7-27.

Gartner, J. W. 2004. Estimating suspended solids concentrations from backscatter intensity measured by acoustic Doppler current profiler in San Francisco Bay, California. Marine Geology 211(3-4): 169-187.

Gilmour, J. 1999. Experimental investigation into the effects of suspended sediment on fertilization, larval survival and settlement in a scleractinian coral. Marine Biology 135(3): 451-462.

Gireeshkumar, T. R., P. M. Deepulal, and N. Chandramohanakumar. 2013. Distribution and sources of sedimentary organic matter in a tropical estuary, southwest coast of India (Chochin estuary): A baseline study. Marine Pollution Bulletin 66(1-2): 239-245.

Goh, B. P. L., and L. M. Chou. 1997. Heavy metal levels in marine sediments of Singapore. Environmental Monitoring and Assessment 44(1): 67-80.

Goni, M. A., K. C. Ruttenberg, and T. I. Eglinton. 1998. A reassessment of the sources and importance of land-derived organic matter in surface sediments from the Gulf of Mexico. Geochimica et Cosmochimica Acta 62(18): 3055-3075.

Goodbred, S. L., and S. A. Kuehl. 1998. Floodplain processes in the Bengal Basin and the storage of Ganges-Brahmaputra river sediment: An accretion study using ${ }^{137 \mathrm{Cs}}$ and ${ }^{210} \mathrm{~Pb}$ geochronology. Sedimentary Geology 121(3-4): 239-258.

Gordon, E. S., and M. A. Goni. 2003. Sources and distribution of terrigenous organic matter delivered to the Atchafalaya River to sediments in the northern Gulf of Mexico. Geochimica et Cosmochimica Acta 67(13): 2359-2375. 
Gouleau, D., J. M. Jouanneau, O. Weber, and P. G. Sauriau. 200o. Short-and long-term sedimentation on Montportail-Brouage intertidal mudflat, Marennes-Oleron Bay (France). Continental Shelf Research 20(12-13): 1513-1530.

Guerra, R., A. Pasteris, and M. Ponti. 2009. Impacts of maintenance channel dredging in a northern Adriatic coastal lagoon. I: Effects on sediment properties, contamination and toxicity. Estuarine, Coastal and Shelf Science 85(1): 134-142.

Guzman, H. M., and I. Holst. 1993. Effects of chronic oil-sediment pollution on the reproduction of the Caribbean reef coral Siderastrea siderea. Marine Pollution Bulletin 26(5): 276-282.

Hamilton, L. J., Z. Shi, and S. Y. Zhang, 1998. Acoustic backscatter measurements of estuarine suspended cohesive sediment concentration profiles. Journal of Coastal Research 14(4): 1213-1224.

Hancock, G., and G. Caitcheon. 2010. Sediment sources and transport to the LoganAlbert River estuary during the January 2008 flood event. Water for a Healthy Country. Flagship Report, Series ISSN: 835-095X, CSIRO.

Hart, D. D., T. E. Johnson, K. L. Bushaw-Newton, R. J. Horwitz, A. T. Bednarek, D. F. Charles, D. A. Kreeger, and D. J. Velinsky. 2002. Dam removal: Challenges and opportunities for ecological research and river restoration. Bioscience 52(8): $669-681$.

Hedges, J. I., and R. G. Keil. 1995. Sedimentary organic matter preservation: an assessment and speculative synthesis. Marine Chemistry 49(2): 81-115.

Hitchcock, D.R., and S. Bell. 2004. Physical impacts of marine aggregate dredging on seabed resources in coastal deposits. Journal of Coastal Research 20(1): 101-114.

Hoefs, J. 2009. Isotope fractionation processes of selected elements. Stable Isotope Geochemistry, $7^{\text {th }}$ Edition. New York: Springer International Publishing.

Jaffe, R., R. Mead, M. E. Hernandez, M. C. Peralba, and O. A. DiGuida. 2001. Origin and transport of sedimentary organic matter in two subtropical estuaries: A comparative, biomarker-based study. Organic Geochemistry 32(4): 507-526.

Johnston, S. A. 1981. Estuarine dredge and fill activities: A review of impacts. Environmental Management 5 (5): 427-440.

Jorgensen, P. V., and K. Edelvang. 2000. CASI data utilized for mapping suspended matter concentrations in sediment plumes and verification of $2 \mathrm{D}$ hydrodynamic modeling. International Journal of Remote Sensing 21(11): 2247-2258.

Jweda, J., M. Baskaran, E. van Hees, and L. Schweitzer. 2008. Short-lived radionuclides $\left(7 \mathrm{Be}\right.$ and $\left.{ }^{210} \mathrm{~Pb}\right)$ as tracers of particle dynamics in a river system in southeast Michigan. Limnology and Oceanography 53(5): 1934-1944.

Kim, C. S., and H-K. Lim. 2009. Sediment dispersal and deposition due to sand mining in the coastal waters of Korea. Continental Shelf Research 1(15): 194-204. 
Kirchner, G. 2011. ${ }^{210} \mathrm{~Pb}$ as a tool for establishing sediment chronologies: Examples of potentials and limitations of conventional dating models. Journal of Environmental Radioactivity 102(5): 490-494.

Krishnáswami, S., L. K. Benninger, R. C. Aller, and K. L. Von Damm. 1980. Atmospherically-derived radionuclides as tracers of sediment mixing and accumulation in near-shore marine and lake sediments: Evidence from ${ }^{7 \mathrm{Be}},{ }^{210} \mathrm{~Pb}$, and 239, 240 Pu. Earth and Planetary Science Letters 47(3): 307-318.

Land, J. M., and R. N. Bray. 2000. Acoustic measurement of suspended solids for monitoring of dredging and dredged material disposal. Journal of Dredging Engineering 2(3): 1-17.

Lewis, M. A., D. E. Weber, R. S. Stanley, and J. C. Moore. 2001. Dredging impact on an urbanized Florida bayou: Effects on benthos and algal-periphyton. Environmental Pollution 115(2): 161-171.

Maksymowska, D., P. Richard, H. Piekarek-Janowska, and P. Riera. 200o. Chemical and isotopic composition of the organic matter sources in the Gulf of Gdansk (Southern Baltic Sea). Estuarine, Coastal and Shelf Science 51(5): 585-598.

Mathangwane, B. T., M. A. Chappell, J. R. V. Pils, L. S. Sonon, and V. P. Evangelou. 2008. Dispersion potential of selected Iowa lake sediments as influenced by dissolved and solid-phase constituents. CLEAN-Soil, Air, Water 36(2): 201-208.

Matisoff, G., C. G. Wilson, and P. J. Whiting. 2005. The $7 \mathrm{Be} / 210 \mathrm{~Pb}$ ratio as an indicator of suspended sediment age or fraction new sediment in suspension. Earth Surface Processes and Landforms 30(9): 1191-1201.

McKee, B. A., C. A. Nittrouer, and D. J. DeMaster. 1983. Concepts of sediment deposition and accumulation applied to the continental shelf near the mouth of the Yangtze River. Geology 11(11): 631-633.

Meyers, P. A. 1994. Preservation of elemental and isotopic source identification of sedimentary organic matter. Chemical Geology 144(3-4): 289-302.

Meyers, P. A. 1997. Organic geochemical proxies of paleoceanographic, paleolimnologic, and paleoclimatic processes. Organic Geochemistry 27(5/6): 213-250.

Miller, R. L., and J. F. Cruise. 1995. Effects of suspended sediments on coral growth: evidence from remote sensing and hydrologic modeling. Remote sensing of Environment 53(3): 177-187.

Mullenbach, B. L., and C. A. Nittrouer. 2000. Rapid deposition of fluvial sediment in the Eel Canyon, northern California. Continental Shelf Research 20(16): 2191-2212.

Mullenbach, B. L., C. A. Nittrouer, P. Puig, and D. L. Orange. 2004. Sediment deposition in a modern submarine canyon: Eel Canyon, northern California. Marine Geology 211(1-2): 101-119.

Nayar, S., B. P. L. Goh, L. M. Chou, and S. Reddy. 2003. In situ microcosms to study the impact of heavy metals resuspended by dredging on periphyton in a tropical estuary. Aquatic Toxicology 64(3): 293-306. 
Nayar, S., D. J. Miller, A. Hunt, B. P. L. Goh, and L. M. Chou. 2007. Environmental effects of dredging on sediment nutrients, carbon and granulometry in a tropical estuary. Environmental Monitoring Assessment 127(1): 1-13.

Newell, R. C., L. J. Seiderer, and D. R. Hitchcock. 1998. The impact of dredging works in coastal waters: a review of the sensitivity to disturbance and subsequent recovery of biological resources on the sea bed. Oceanography and Marine Biology 36: 127-178.

Nichols, M., R. J. Diaz, and L. C. Schaffner. 1990. Effects of hopper dredging and sediment dispersion, Chesapeake Bay. Environmental Geology and Water Sciences 15(1): 31-43.

Nittrouer, C. A., J. A. Austin, M. E. Field, J. H. Kravitz, J. P. Syvitski, and P. L. Wiberg, eds. 2009. Continental margin sedimentation: From sediment transport to sequence stratigraphy (special publication 37 of the IAS) (Vol. 25). Hoboken: John Wiley \& Sons.

Noakes, S. E., and P. C. Jutte. 2006. Utilizing gamma isotope tracers to determine sediment source at reef sites near the Charleston Ocean Dredged Material Disposal Site. Marine Pollution Bulletin 52(6): 666-673.

Palmer, H. D., and M. G. Gross. 1979. Ocean dumping and marine pollution: Geological aspects of waste disposal. Stroudsburg, PA: Dowden, Hutchinson \& Ross, Inc.

Papanicolaou, A. N., J. F. Fox, and J. Marshall. 2003. Soil fingerprinting in the Palouse Basin, USA, using stable carbon and nitrogen isotopes. International Journal of Sediment Research 18(2): 278-284.

Patchineelam, S. M., B. Kjerfve, and R. A. Gardner. 1999. A preliminary sediment budget for the Winyah Bay estuary, South Carolina, USA. Marine Geology 62(1): 133144 .

Perrin, C. J., K. I. Ashley, and G. A. Larkin. 2000. Effect of drawdown on ammonium and iron concentrations in a coastal mountain reservoir. Water Quality Research Journal of Canada 35(2): 231-244.

Peterson, R. N. 2009. Natural radionuclide applications for riverine and coastal marine investigations. Doctoral dissertation. Florida State University, College of Arts and Sciences, Department of Physical Oceanography.

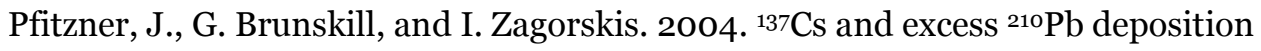
patterns in estuarine and marine sediment in the central region of the Great Barrier Reef Lagoon, north-eastern Australia. Journal of Environmental Radioactivity 76(1-2): 81-102.

Prahl, F. G., J. T. Bennett, and R. Carpenter. 1980. The early diagenesis of aliphatic hydrocarbons and organic matter in sedimentary particles from Dabob Bay, Washington. Geochemica et Cosmochimica Acta 44: 1967-1976.

Prahl, F. G., J. R. Ertel, M. A. Goni, M. A. Sparrow, and B. Eversmeyer. 1994. Terrestrial organic carbon contributions to sediments on the Washington margin.

Geochemica et Cosmochimica Acta 58(14): 3035-3048. 
Pranovi, F., F. Da Ponte, S. Raicevich, and O. Giovanardi. 2004. A multidisciplinary study of the immediate effects of mechanical clam harvesting in the Venice Lagoon. ICES Journal of Marine Science 61(1): 43-52.

Ravichandran, M., M. Baskaran, P. H. Santschi, and T. S. Bianchi. 1995. Geochronology of sediments in the Sabine-Neches estuary, Texas, U.S.A. Chemical Geology 125 (3-4): 291-306.

Redfield, A. C., B. H. Ketchum, and F. A. Richard. 1963. The influence of organisms on the composition of sea water. In The Sea, M. N. Hill (ed.), 26-49. New York: Wiley.

Reine, K. J., D. G. Clark, and C. Dickerson. 2002. Acoustic characterization of suspended sediment plumes resulting from barge overflow. DOER Technical Notes Collection. ERDC-TN-DOER-E15. Vicksburg, MS: U.S. Army Research and Development Center.

Rhoads, D. C., P. L. McCall, and J. Y. Yingst. 1978. Disturbance and production on the estuarine seafloor: Dredge-spoil disposal in estuaries such as Long Island Sound can be managed in ways that enhance productivity rather than diminish it. American Scientist 66(5): 577-586.

Riegl, B., and G. M. Branch. 1995. Effects of sediment on the energy budgets of four scleractinian (Bourne 1900) and five alcyonacean (Lamouroux 1816) corals. Journal of Experimental Marine Biology and Ecology 186(2): 259-275.

Ritchie, J. C., and J. R. McHenry. 1990.Application of radioactive fallout cesium-137 for measuring soil erosion and sediment accumulation rates and patterns: a review. Journal of Environmental Quality Apr/June 1990 19(2): 215-233.

Rubio, L., A. Linares-Reuda, C. Dueñas, M. C. Fernández, V. Clavero, F. X. Niell, and J. A. Fenández. 2003. Sediment accumulation rate and radiological characterization of the sediment of the Palmones River estuary (southern of Spain). Journal of Environmental Radioactivity 65(3): 267-280.

Rumolo, P., M. Barra, S. Gherardi, E. Marsella, and M. Sprovieri. 2011. Stable isotopes and $\mathrm{C} / \mathrm{N}$ ratios in marine sediments as a tool for discriminating anthropogenic impact. Journal of Environmental Monitoring 13: 3399-3408.

Saari, H. K., S. Schmidt, P. Castaing, G. Blanc, B. Sautour, O. Masson, and J. K. Cochran.

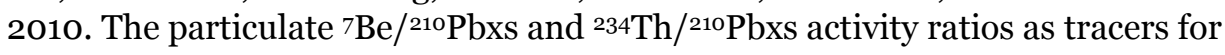
tidal-to-seasonal particle dynamics in the Gironde estuary (France): Implications for the budget of particle-associated contaminants. Science of the Total Environment 408(20): 4784-4794.

Santschi, P. H., S. Nixon, M. Pilson, and C. Hunt. 1984. Accumulation of sediments, trace metals $(\mathrm{Pb}, \mathrm{Cu})$ and total hydrocarbons in Narragansett Bay, Rhode Island. Estuarine, Coastal and Shelf Science 19(4): 427-449.

Savoye, N., C. Benitez-Nelson, A. B. Burd, J. K. Cochran, M. Charette, K. O. Buesseler, G. A. Jackson, M. Roy-Barman, S. Schmidt, and M. Elskens. 2006. ${ }^{234}$ Th sorption and export models in the water column: A review. Marine Chemistry 100(3-4): 234-249. 
Sharma, P., L. R. Gardner, W. S. Moore, and M. S. Bollinger. 1987. Sedimentation and

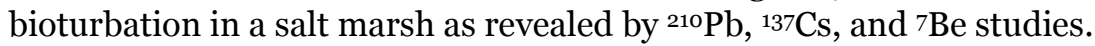
Limnology and Oceanography 32(2): 313-326.

Simms, A. D., C. Woodroffe, B. G. Jones, H. Heijnis, R. A. Mann, and J. Harrison. 2008. Use of ${ }^{210} \mathrm{~Pb}$ and ${ }^{137} \mathrm{Cs}$ to simultaneously constrain ages and sources of post-dam sediments in the Cordeaux reservoir, Sydney, Australia. Journal of Environmental Radioactivity 99(7): 1111-1120.

Smith, G. G., N. Weitz, C. Soultau, A. Viljoen, S. Luger, and L. Maartens. 2008. Fate of fine sediment from dredger-based mining in a wave-dominated environment at Chameis Bay, Namibia. Journal of Coastal Research 24(1): 232-247.

Sommerfield, C. K. 2006. On sediment accumulation rates and stratigraphic completeness: Lessons from Holocene ocean margins. Continental Shelf Research 26(17-18): 2225-2240.

Sommerfield, C. K., and C. A. Nittrouer. 1999. Modern accumulation rates and a sediment budget for the Eel shelf: A flood-dominated depositional environment. Marine Geology 154(1-4): 227-241.

Stanley, E. H., and M. W. Doyle. 2003. Trading off: The ecological effects of dam removal. Frontiers in Ecology and the Environment 1(1): 15-22.

Steevens, J., A. J. Bednar, J. Brame, M. Chappell, A. J. Kennedy, J. Seiter, and J. Stanley. 2011. Evaluation of metals release from oxidation of fly ash during dredging of the Emory River, TN. ERDC/EL TR-11-9. Vicksburg, MS: U.S. Army Engineer Research and Development Center.

Sugai, S. F. 1990. Transport and sediment accumulation of ${ }^{210} \mathrm{~Pb}$ and ${ }^{137} \mathrm{Cs}$ in two Southeast Alaskan fjords. Estuaries and Coasts 13(4): 380-392.

Sustar, J. F., T. H. Wakeman, and R. M. Ecker. 1976. Sediment-water interaction during dredging operations. In ASCE Proceedings of the Specialty Conference on Dredging and Its Environmental Effects, Mobile, AL, January 26-28.

Taylor, J. L., and C. H. Saloman. 1968. Some effects of hydraulic dredging and coastal development in Boca Ciega Bay, Florida. Fishery Bulletin 67(2): 213-241.

Telesnicki, G. J., and W. M. Goldberg. 1995. Effects of turbidity on the photosynthesis and respiration of two south Florida reef coral species. Bulletin of Marine Science 57(2): 527-539.

Thieler, E. R., P. T. Gayes, W. C. Schwab, and M. S. Harris. 1999. Tracing sediment dispersal on nourished beaches: Two case studies. In Proceedings of the International Conference on Coastal Engineering and Science of Coastal Sediment Processes 4(3): 2118-2136.

Toole, J., M. S. Baxter, and J. Thomson. 1987. The behavior of uranium isotopes with salinity change in three U.K. estuaries. Estuarine, Coastal and Shelf Science 25(3): 83-297. 
Van den Hurk, P., R. H. Eertman, and J. Stronkhorst. 1997. Toxicity of harbor canal sediments before dredging and after off-shore disposal. Marine Pollution Bulletin 34(4): 244-249.

Volger, S., M. Jung, and A. Mangini. 1996. Scavenging of 234Th and 7Be in Lake Constance. Limnology and Oceanography 41(7): 1384-1393.

Waples, J. T., C. Benitez-Nelson, N. Savoye, M. Rutgers van der Loeff, M. Baskaran, and O. Gustafsson. 2006. An introduction to the application and future use of ${ }^{234} \mathrm{Th}$ in aquatic systems. Marine Chemistry 100(3-4): 166-189.

Walling, D. E. 2005. Tracing suspended sediment sources in catchments and river systems. Science of the Total Environment 344(1): 159-185.

Whiting, P. J., G. Matisoff, W. F. Fornes, and F. M. Soster. 2005. Suspended sediment sources and transport distances in the Yellowstone River basin. Geological Society of America Bulletin 117(3-4): 515-529.

Wilson, C. G., G. Matisoff, and P. J. Whiting. 2003. Short-term erosion rates from a $7 \mathrm{Be}$ inventory balance. Earth Surface Processes and Landforms 28(9): 967-977.

Wilson, C. G., G. Matisoff, P. J. Whiting, and D. M. Klarer. 2005. Transport of fine sediment through a wetland using radionuclide tracers: Old Woman Creek, OH. Journal of Great Lakes Research 31(1): 56-67.

Wilson, C. G., G. Matisoff, and P. J. Whiting. 2007. The use of $7 \mathrm{Be}$ and ${ }^{210} \mathrm{~Pb}$ to differentiate fine suspended sediment sources in South Slough, Oregon. Estuaries and Coasts 30(2): 348-358.

Wilson, C. G., R. A. Kuhnle, D. D. Bosch, J. L. Steiner, P. J. Starks, M. D. Tomer, and G. V. Wilson. 2008. Quantifying relative contributions from sediment sources in Conservation Effects Assessment Project watersheds. Journal of Soil and Water Conservation 63(6): 523-532.

Wirth, E. F., G. I. Scott, M. H. Fulton, R. F. Van Dolah, P. P. Maier, N. Hadley, J. W. Daugoman, and J. P. Key. 1996. In situ monitoring of dredged material spoil sites using the oyster Crassostrea virginica. Archives of Environmental Contamination and Toxicology 30(3): 340-348.

Wu, G., W. J. Leeu, A. K. Skidmore, H. H. T. Prins, and Y. Liu. 2007. Concurrent monitoring of vessels and water turbidity enhances the strength of evidence in remotely sensed dredging impact assessment. Water Research 41(15): 32713280 .

Yozzo, D. J., P. Wilber, and R. J. Will. 2004. Beneficial use of dredged material for habitat creation, enhancement and restoration in New York - New Jersey Harbor. Journal of Environmental Management 73(1): 39-52.

Zwolsman, J. J. G., G. W. Berger, and G. T. M. Van Eck. 1993. Sediment accumulation rates, historical input, post-depositional mobility and retention of major elements and trace metals in salt marsh sediments of the Scheldt estuary, SW Netherlands. Marine Chemistry 44(1): 73-94. 


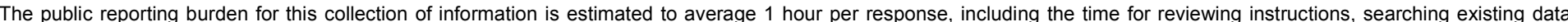

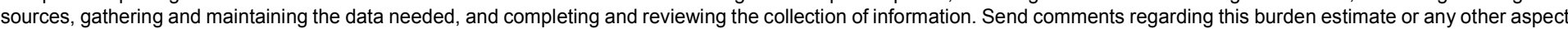

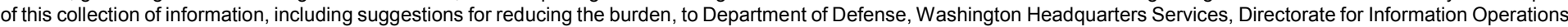

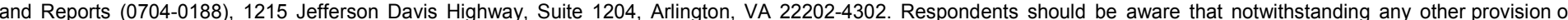
law, no person shall be subject to any penalty for failing to comply with a collection of information if it does not display a currently valid OMB control number.

PLEASE DO NOT RETURN YOUR FORM TO THE ABOVE ADDRESS.

\begin{tabular}{l|l|l}
$\begin{array}{l}\text { 1. REPORT DATE } \\
\text { June } 2017\end{array}$ & $\begin{array}{l}\text { 2. REPORT TYPE } \\
\text { Final }\end{array}$ & 3. DATES COVERED (FrOm - To)
\end{tabular}

\section{TITLE AND SUBTITLE}

Final

A Guide for Using Geochemical Methods in Dredged Material, Sediment Tracking, and Sediment Budget Studies

5a. CONTRACT NUMBER

5b. GRANT NUMBER

5c. PROGRAM ELEMENT NUMBER

6. AUTHOR(S)

Heidi M, Wadman, David W. Perkey, Jennifer M. Seiter, Mark A. Chappell,

Brandon Lafferty

5d. PROJECT NUMBER

449021

5e. TASK NUMBER

5f. WORK UNIT NUMBER

\section{PERFORMING ORGANIZATION NAME(S) AND ADDRESS(ES)}

Engineering Research and Development Center, Coastal and Hydraulics

Laboratory's Field Research Facility, 1261 Duck Rd, Kitty Hawk, NC, 27949

Engineering Research and Development Center, Coastal and Hydraulics Laboratory

and Environmental Laboratory, 3909 Halls Ferry Rd, Vicksburg, MS, 39180

\section{SPONSORING/MONITORING AGENCY NAME(S) AND ADDRESS(ES)}

Dredging Operations and Environmental Research, Engineering Research and

Development Center, 3909 Halls Ferry Rd, Vicksburg, MS, 39180
8. PERFORMING ORGANIZATION REPORT NUMBER

ERDC TR-17-3

10. SPONSOR/MONITOR'S ACRONYM(S)

DOER

\section{SPONSOR/MONITOR'S REPORT} NUMBER(S)

\section{DISTRIBUTION/AVAILABILITY STATEMENT}

Approved for public release; distribution is unlimited.

\section{SUPPLEMENTARY NOTES}

\section{ABSTRACT}

Effective regional sediment management has the potential to significantly reduce operating costs for the U.S. Army Corps of Engineers but only if the ultimate sources and sinks of coastal sediment are fully quantified. Geochemical sedimentary markers provide a wellestablished methodology for fingerprinting the various sources and time frames over which sediment accumulates in regions of concern. This report outlines the basic methodology of how different geochemical signatures can be utilized to identify sources and fates of sediment. These methodologies are then showcased in example case studies (real and hypothetical) that address issues pertinent to the mission of the U.S. Army Corps of Engineers.

\section{SUBJECT TERMS}

Coastal sediments, Dredging, Dredge plume tracking, Elemental composition, Geochemical fingerprinting, Geochemistry, Mineralogy, Radioisotopes, Sediment sources and sinks, Sediment control, Sediments (Geology)—Analysis, Sediment tracers, Sediment transport,

Sediment particle size, Stable isotopes

\section{SECURITY CLASSIFICATION OF:} a. REPORT b. ABSTRACT c. Unlimited Unlimited
17. LIMITATION OF ABSTRACT

THIS PAGE Unlimited SAR
18. NUMBER OF PAGES

44 19a. NAME OF RESPONSIBLE PERSON

Heidi M. Wadman

19b. TELEPHONE NUMBER (Include area code) 